Supporting Information

\title{
Versatile hollow ZSM-5 nanoreactors loaded with tailorable metal catalysts for selective hydrogenation reactions
}

Bowen $\mathrm{Li}^{\dagger}$, Kelvin Mingyao Kwok ${ }^{\ddagger}$ and Hua Chun Zeng ${ }^{\star}$

tDepartment of Chemical and Biomolecular Engineering, Faculty of

Engineering, National University of Singapore, 10 Kent Ridge Crescent,

Singapore 119260

‡Department of Process \& Catalysis Research, Institute of Chemical and

Engineering Sciences, A*STAR (Agency for Science, Technology and

Research), 1 Pesek Road, Jurong Island, Singapore 627833

*E-mail: chezhc@nus.edu.sg

Table of Contents

Supporting Figures (Figure S1 to Figure S25) Pages S-2 to S-21

Supporting Tables (Table S1 and S2) Pages S-22 to S-24

References Page S-25 

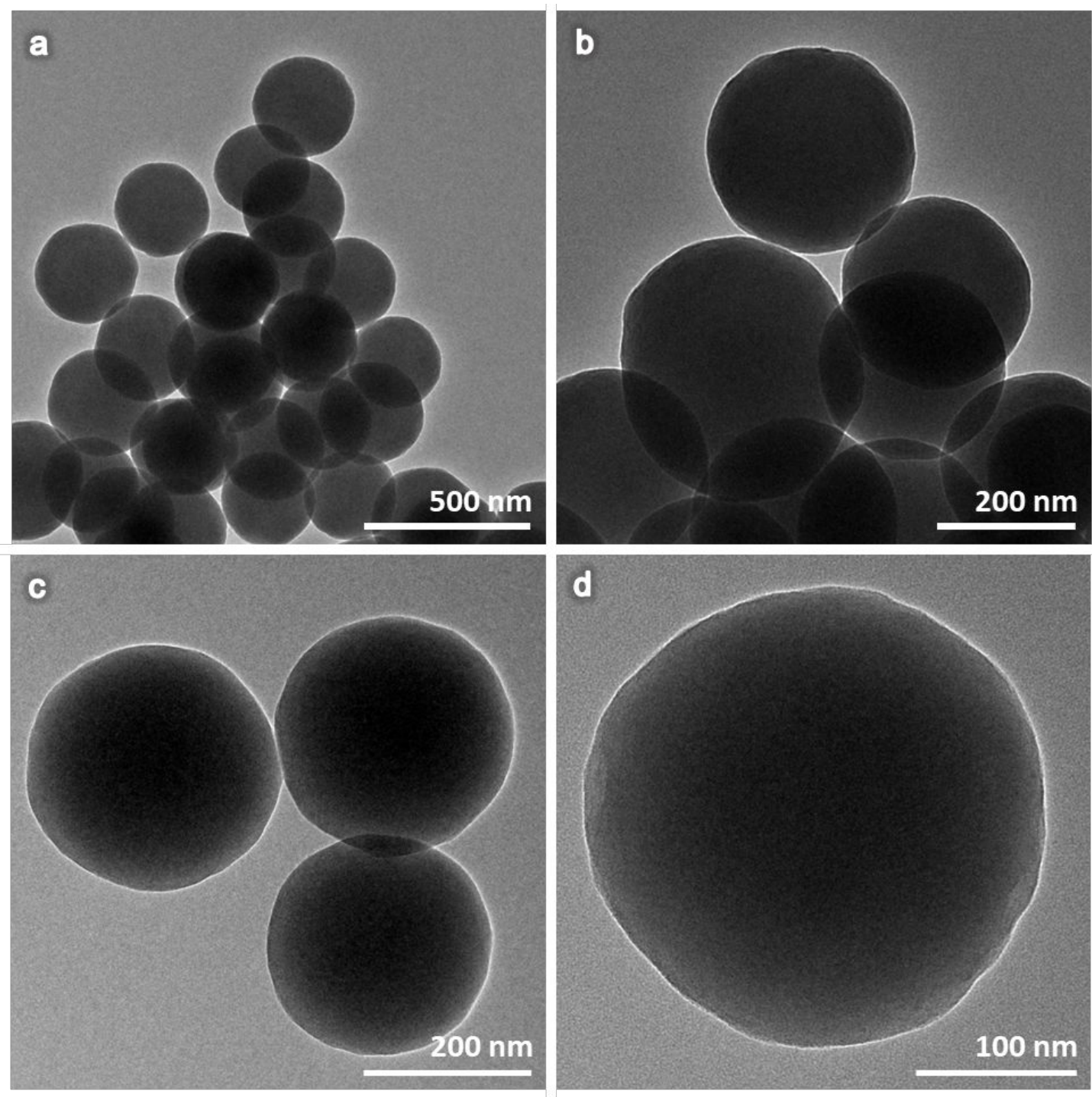

Figure S1. Representative TEM images ((a) to (d) at different magnifications) of $\mathrm{SiO}_{2}$ solid spheres. 

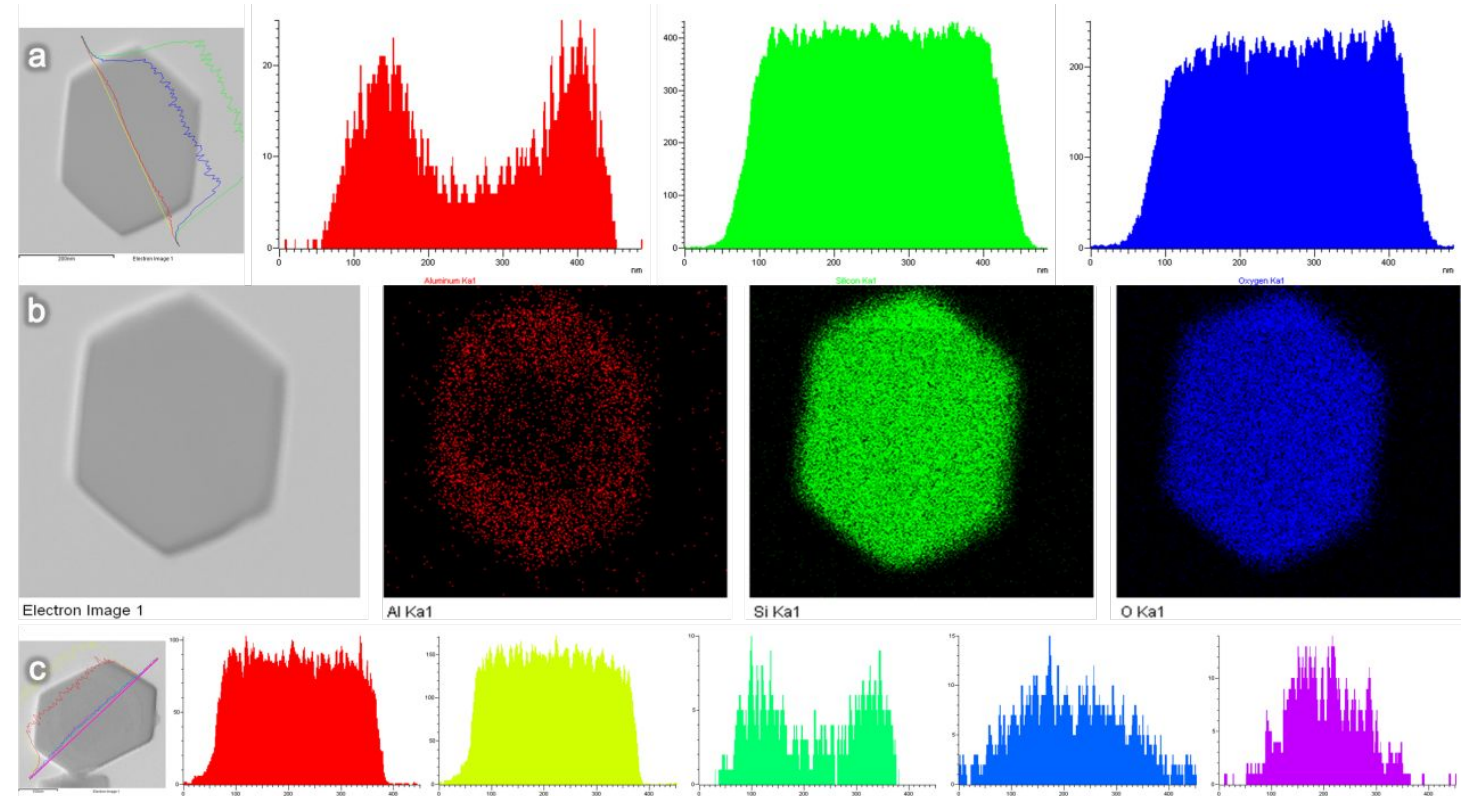

Al Ka1

SiKa1

OKa1
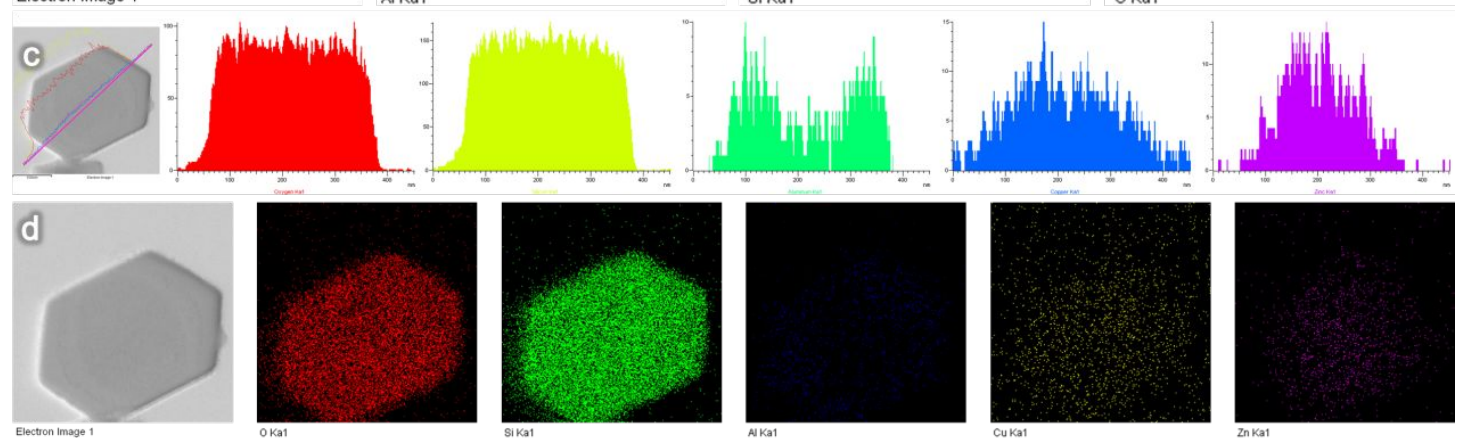

Figure S2. (a) STEM image of a sZ5 crystal and its corresponding EDX line scans; (b) STEM image of a sZ5 crystal and its corresponding EDX mappings; (c) STEM image of a sZ5-CuZn crystal and its corresponding EDX line scans and (d) STEM image of a sZ5-CuZn crystal and its corresponding EDX mappings. Seen from the dual-maxima of Al line scan and the EDX mapping of Al for the sZ5 crystal, there is a clear heterogeneous distribution of $\mathrm{Al}$ with $\mathrm{Al}$-rich surface and $\mathrm{Al}-\mathrm{lean}$ center. Such a distribution of $\mathrm{Al}$ was believed to be a result of using solid $\mathrm{SiO}_{2}$ spheres as precursor for ZSM-5 synthesis. Similar Al line scan was found for sZ5-CuZn sample after metal impregnation. Interestingly, it is noted that the impregnated metals are concentrated at $\mathrm{Al}$-deficient region, since the central region was much more defective as compared to the surface Al-rich region. Thus, the metal deposition was more preferential at such locations. 


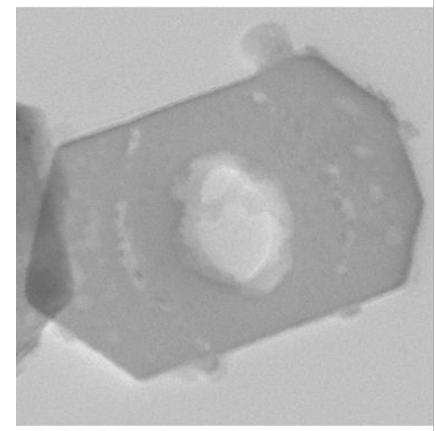

Electron Image 1

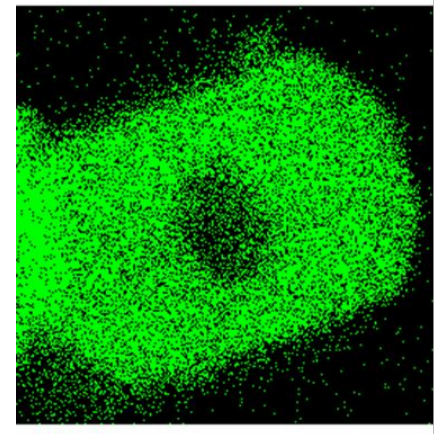

Si Ka1

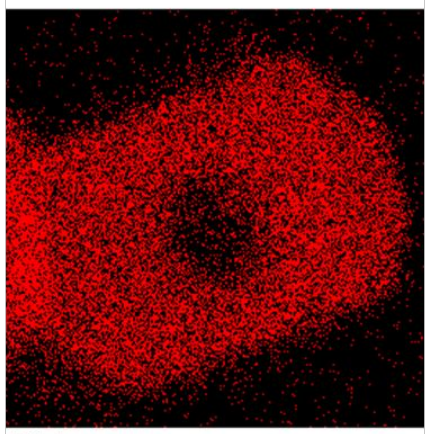

OKa1

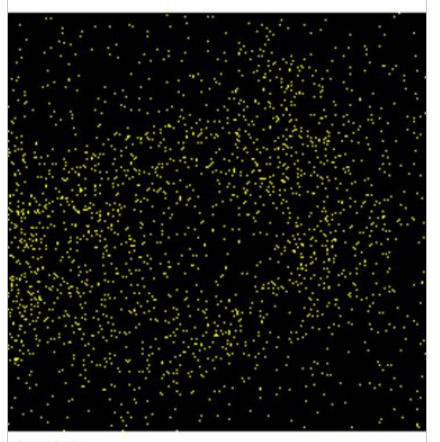

Cu Ka1

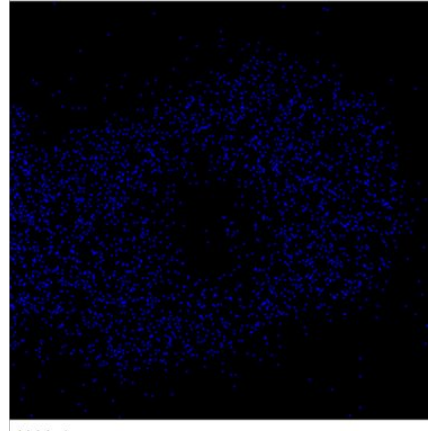

Al Ka1

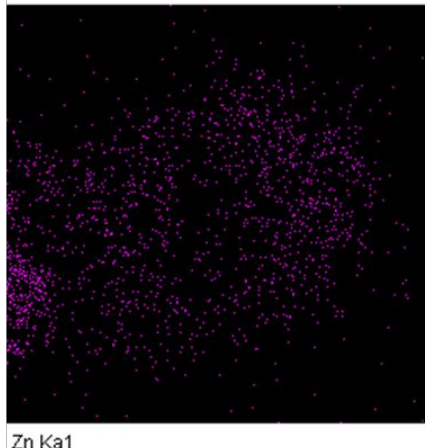

Zn Ka1

Figure S3. STEM image of an hZ5-CuZn crystal synthesized after hydrothermal treatment and its corresponding EDX mappings.
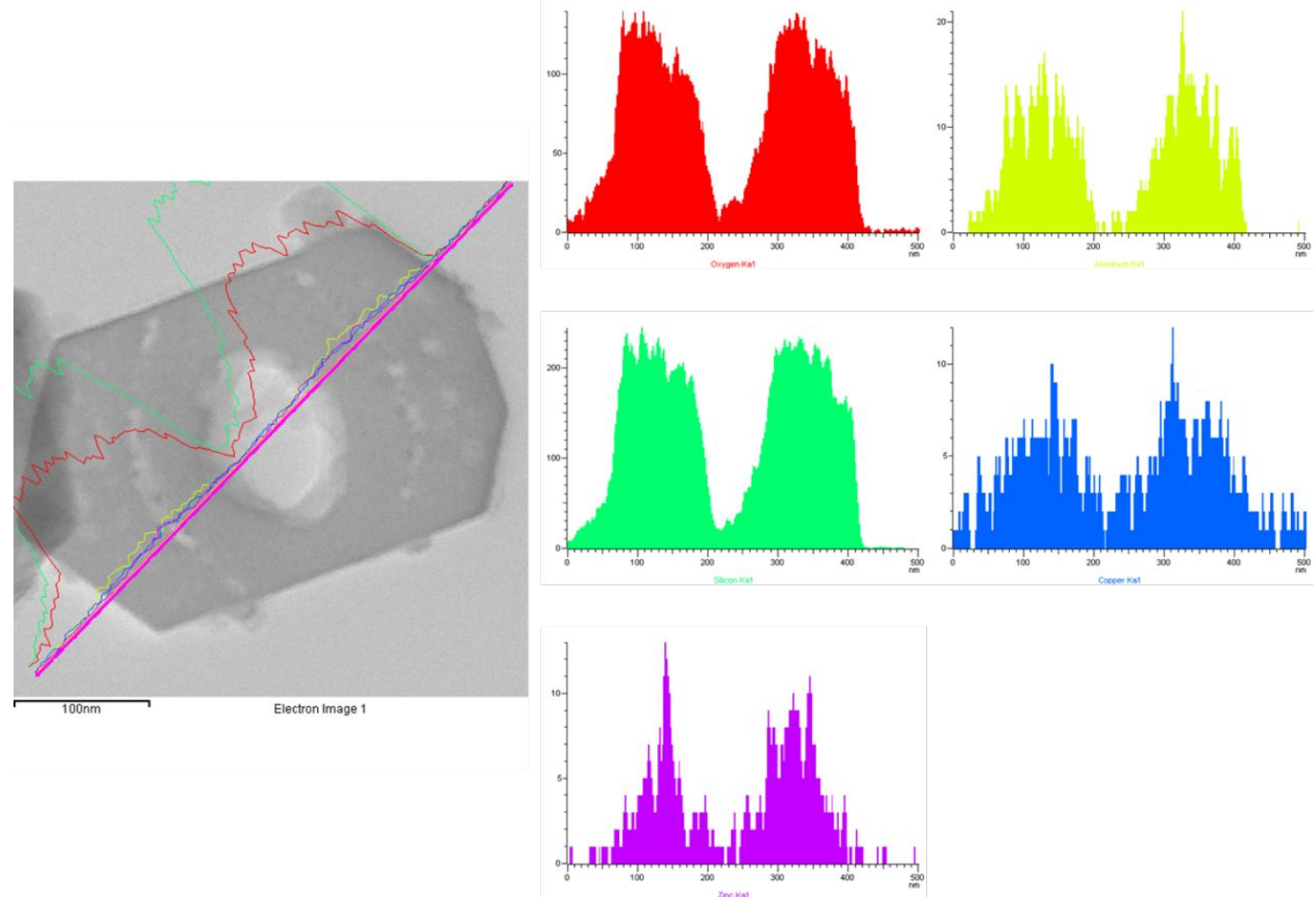

Figure S4. STEM image of an hZ5-CuZn crystal synthesized after hydrothermal treatment and its corresponding EDX line scans. 

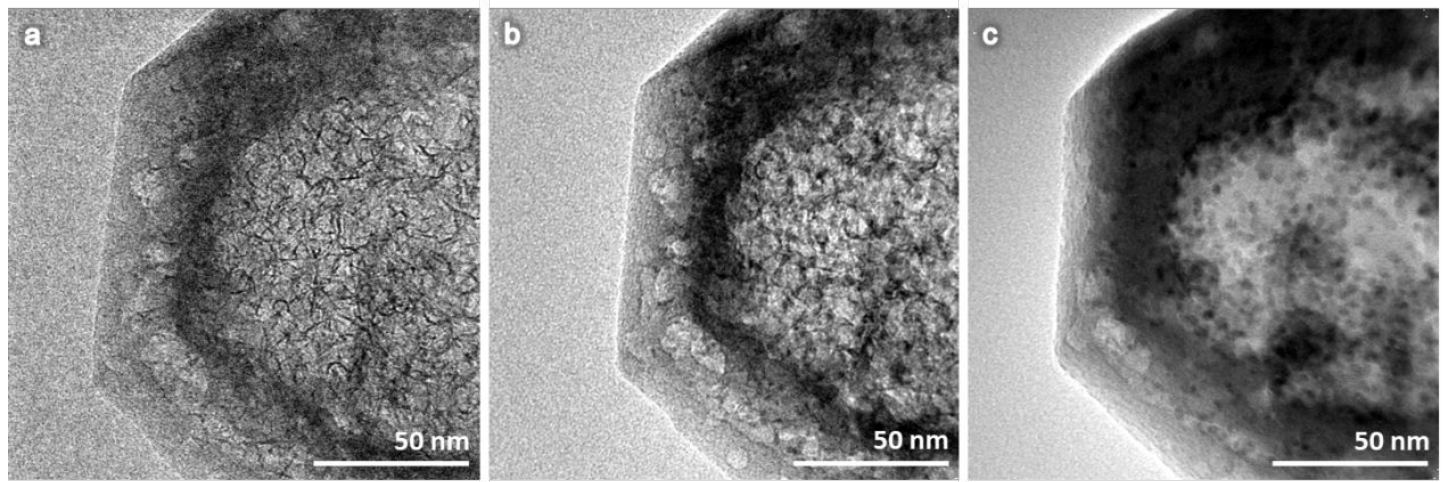

Figure S5. TEM images of the same hZ5-CuZn crystal viewed with (a) low beam intensity, (b) moderate beam intensity and (c) high beam intensity.
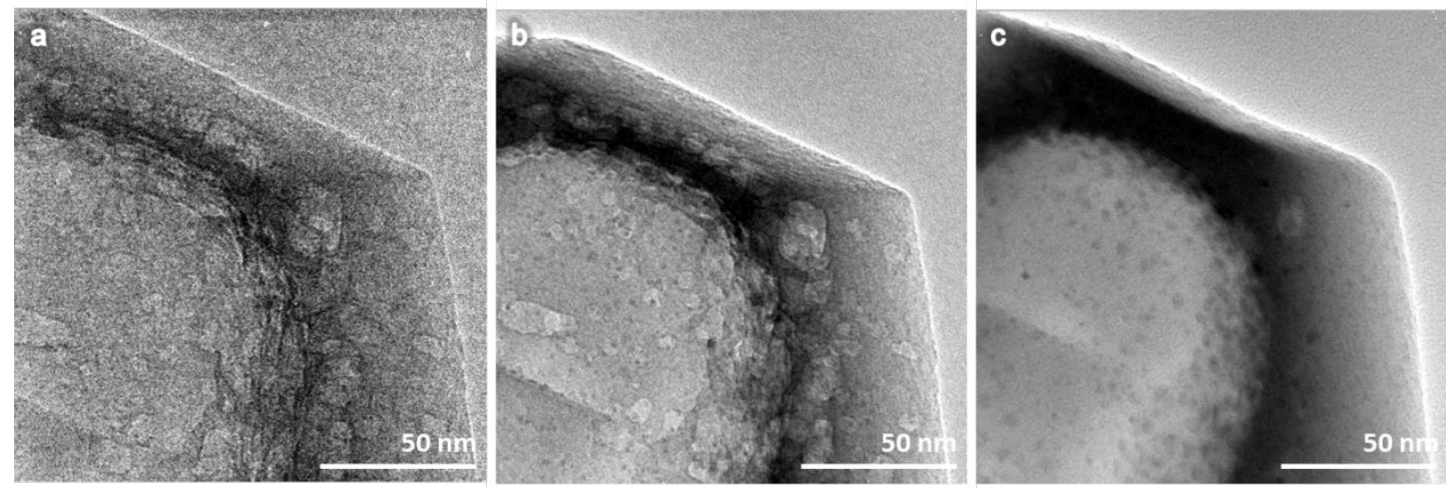

Figure S6. TEM images of the same hZ5-Cu crystal viewed with (a) low beam intensity, (b) moderate beam intensity and (c) high beam intensity. 

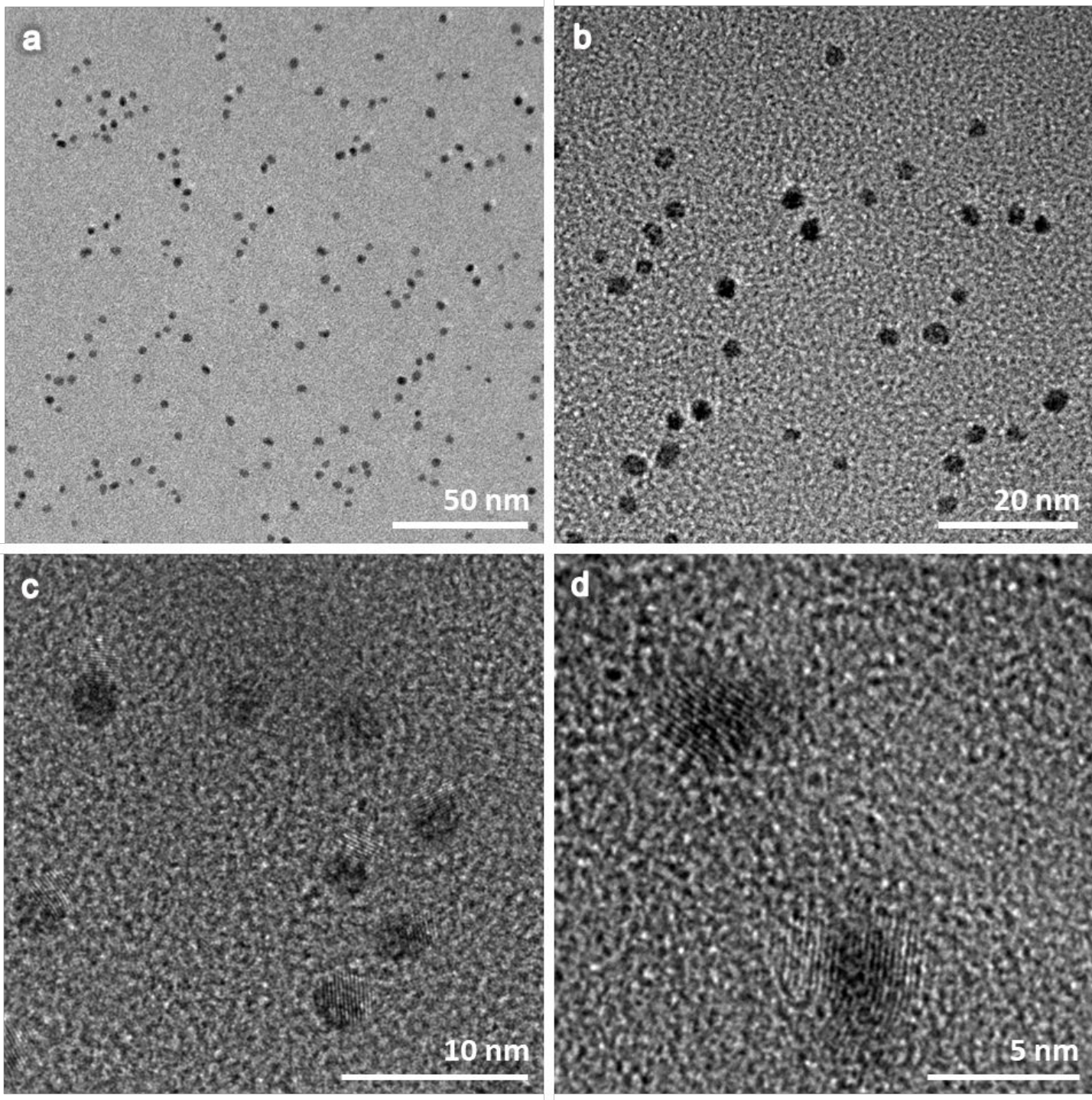

Figure S7. Representative TEM images ((a) to (d) at different magnifications) of Pt NPs synthesized for deposition onto the exterior surface of hZ5-CuZn. 

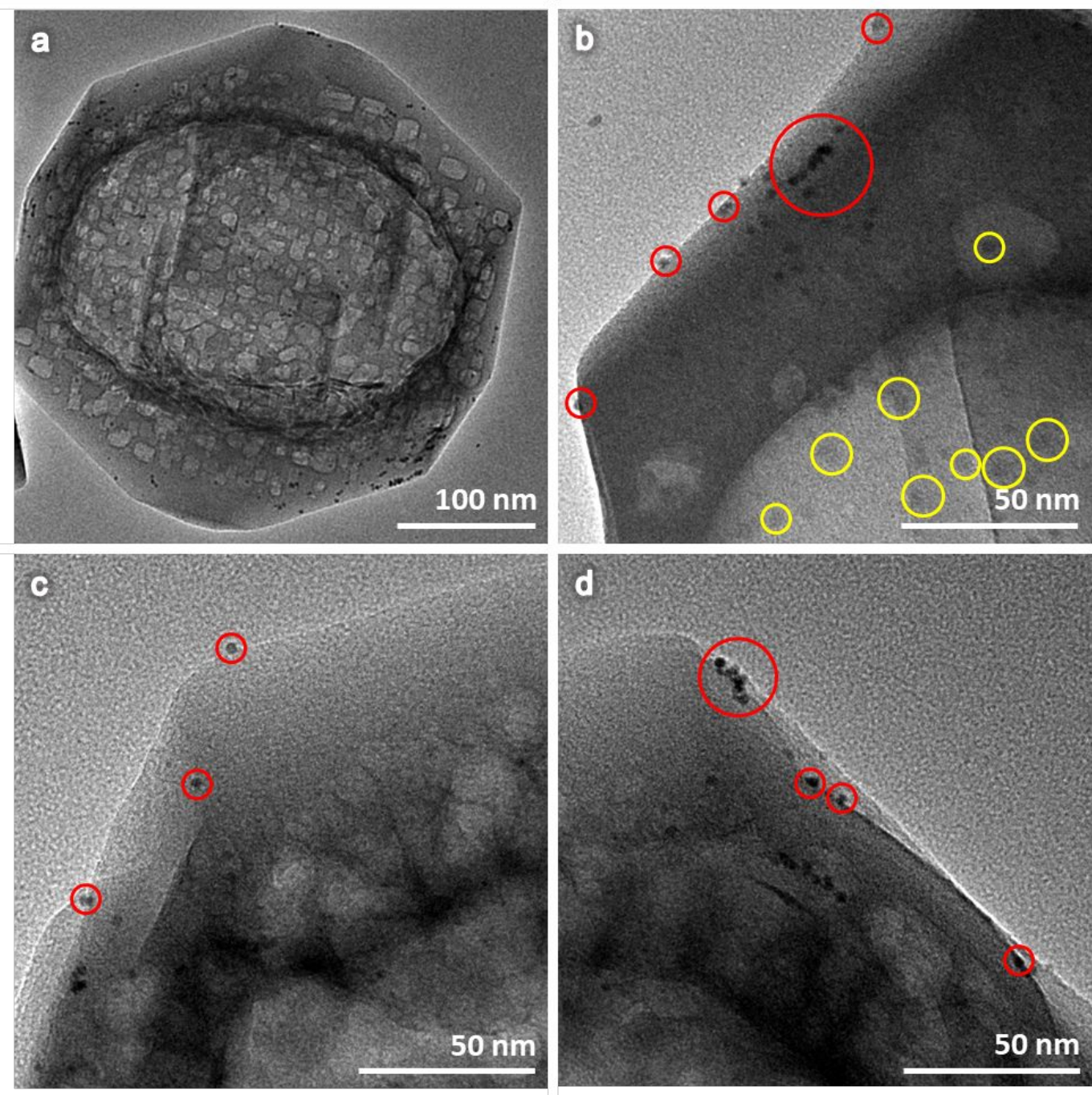

Figure S8. (a-d) Representative TEM images of hZ5-CuZn@Pt at different magnifications. The Pt nanoparticles deposited on the exterior were circled in red. The in-situ reduced CuZn alloy nanoparticles within hollow ZSM-5 were circled in yellow. 

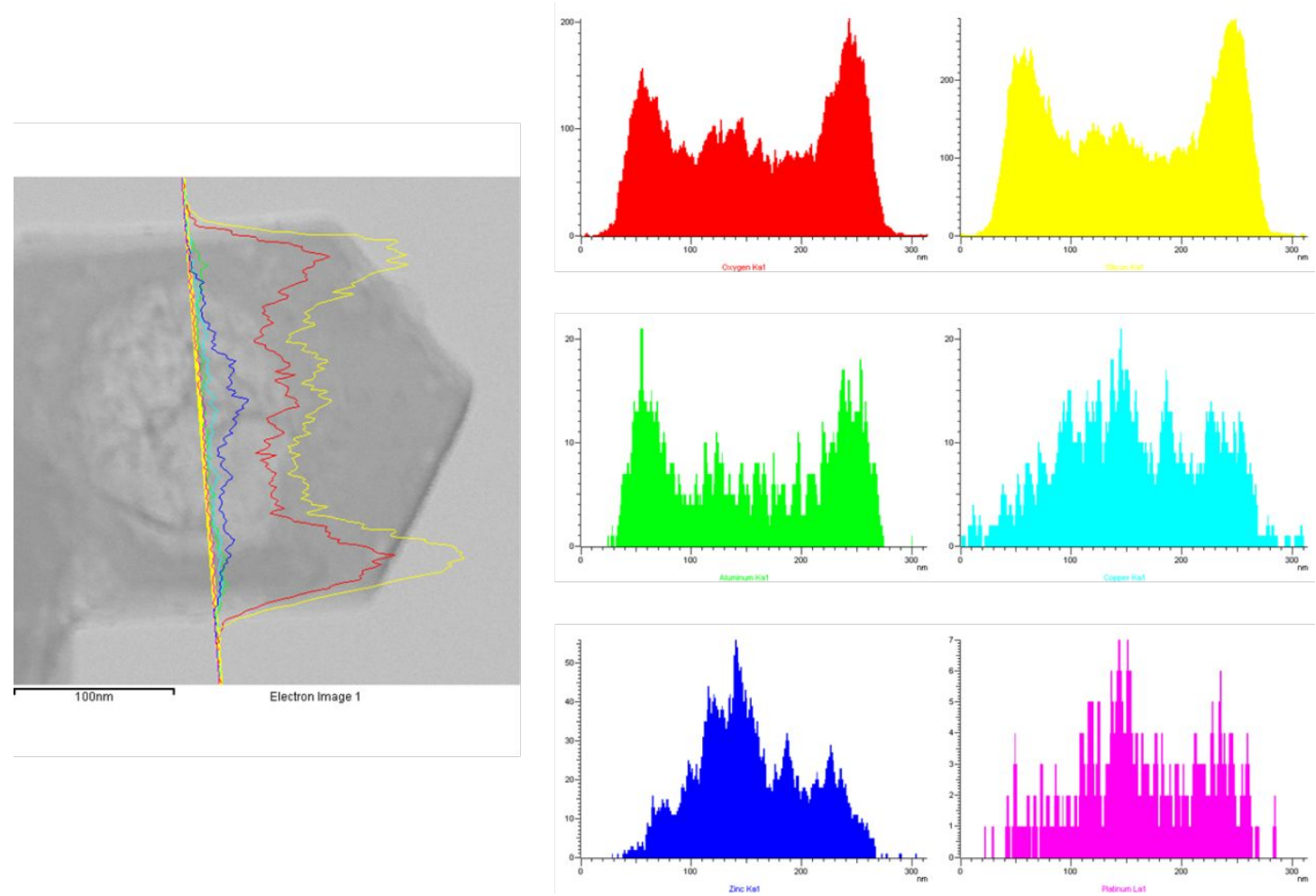

Figure S9. STEM image of a hZ5-CuZn@Pt crystal and its corresponding EDX line scans. 

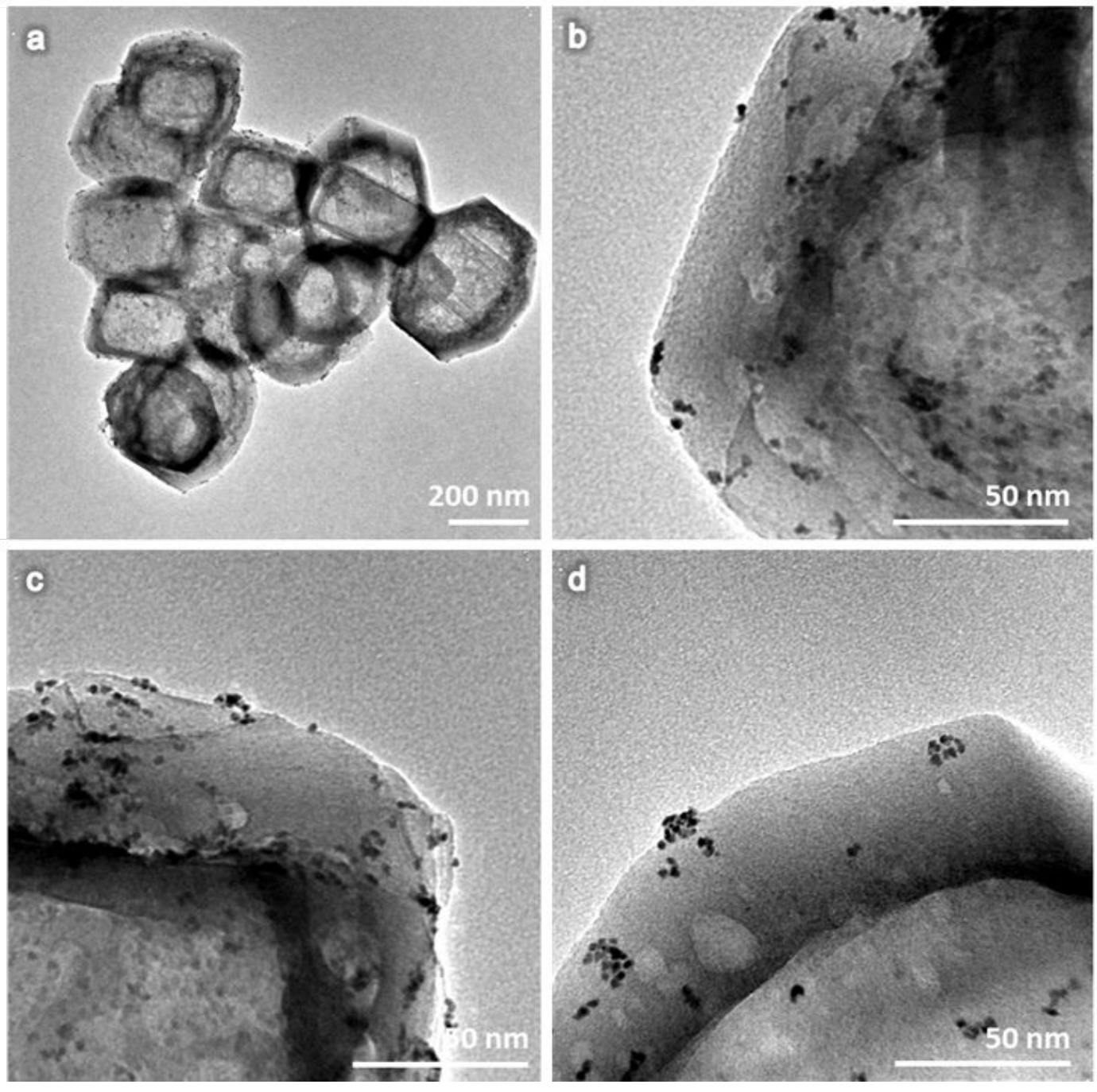

Figure S10. (a-d) Representative TEM images of hZ5-Cu@Pt at different magnifications. The Pt nanoparticles deposited on the exterior were clearly illustrated from TEM images.

This hZ5-Cu@Pt sample was prepared using identical method to that of hZ5CuZn@Pt, except 200 mg of hZ5-Cu sample was used instead of hZ5-CuZn. 

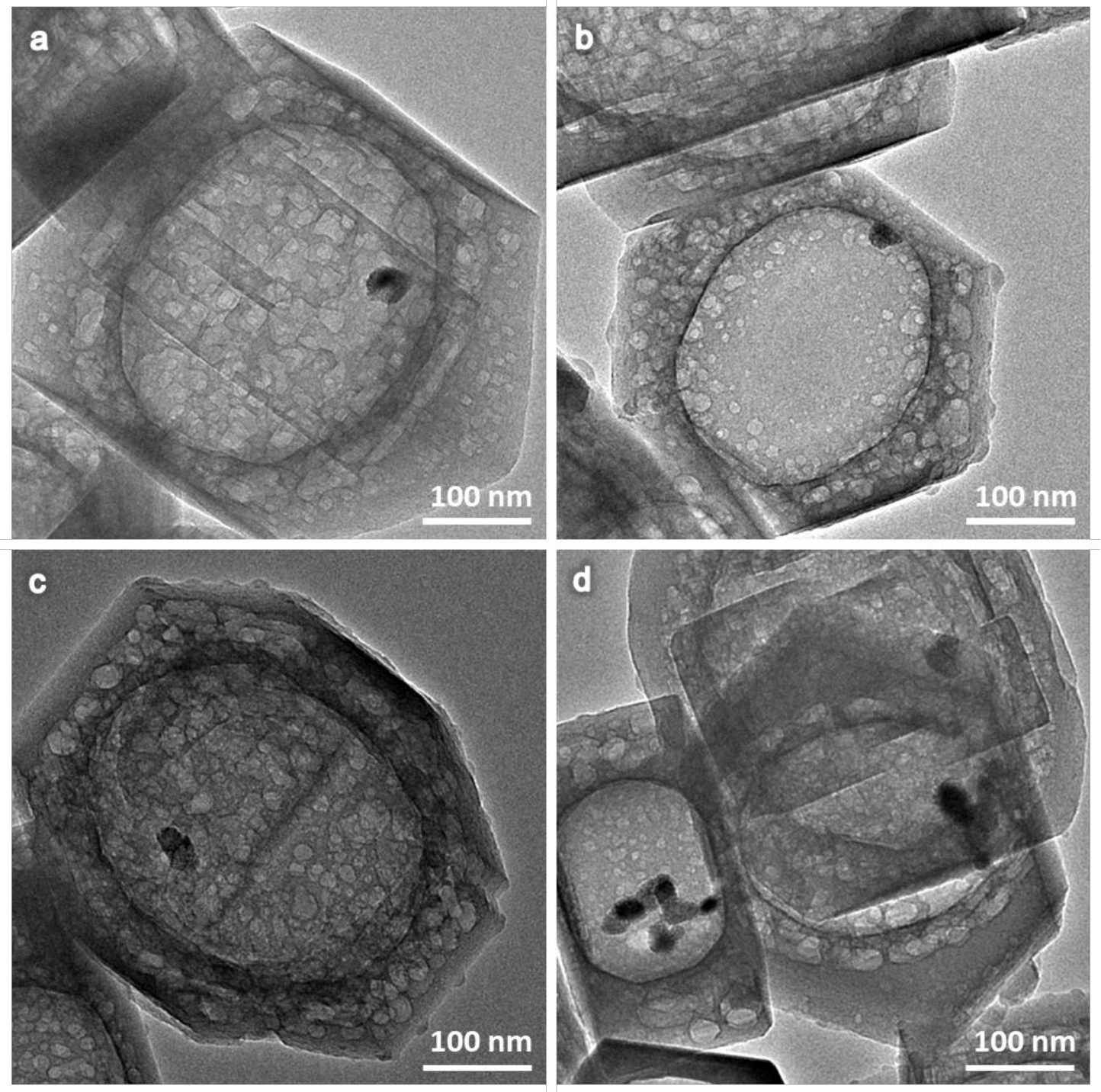

Figure S11. Representative TEM images ((a) to (d)) of hZ5-Pd sample. This sample was synthesized with following conditions: $200 \mathrm{mg}$ of solid sZ5 sample was impregnated with $0.2 \mathrm{~mL}$ of $\mathrm{PdCl}_{2}(0.12 \mathrm{M})$ aqueous solution. This impregnated sample (sZ5-Pd) was dried in $100{ }^{\circ} \mathrm{C}$ for $2 \mathrm{~h}$, followed by calcination in static air at $500{ }^{\circ} \mathrm{C}$ for $4 \mathrm{~h}$. The calcined sample was then subjected to hydrothermal treatment at $170{ }^{\circ} \mathrm{C}$ for $72 \mathrm{~h}$ to produce the above hollow morphology (hZ5-Pd). The resulting $\mathrm{Pd}$ was mobile and easy to aggregate when the interior Al-deficient region was hollowing. Therefore, eventually, the yolk-shell configuration with a single Pd core was seen in the TEM images. 

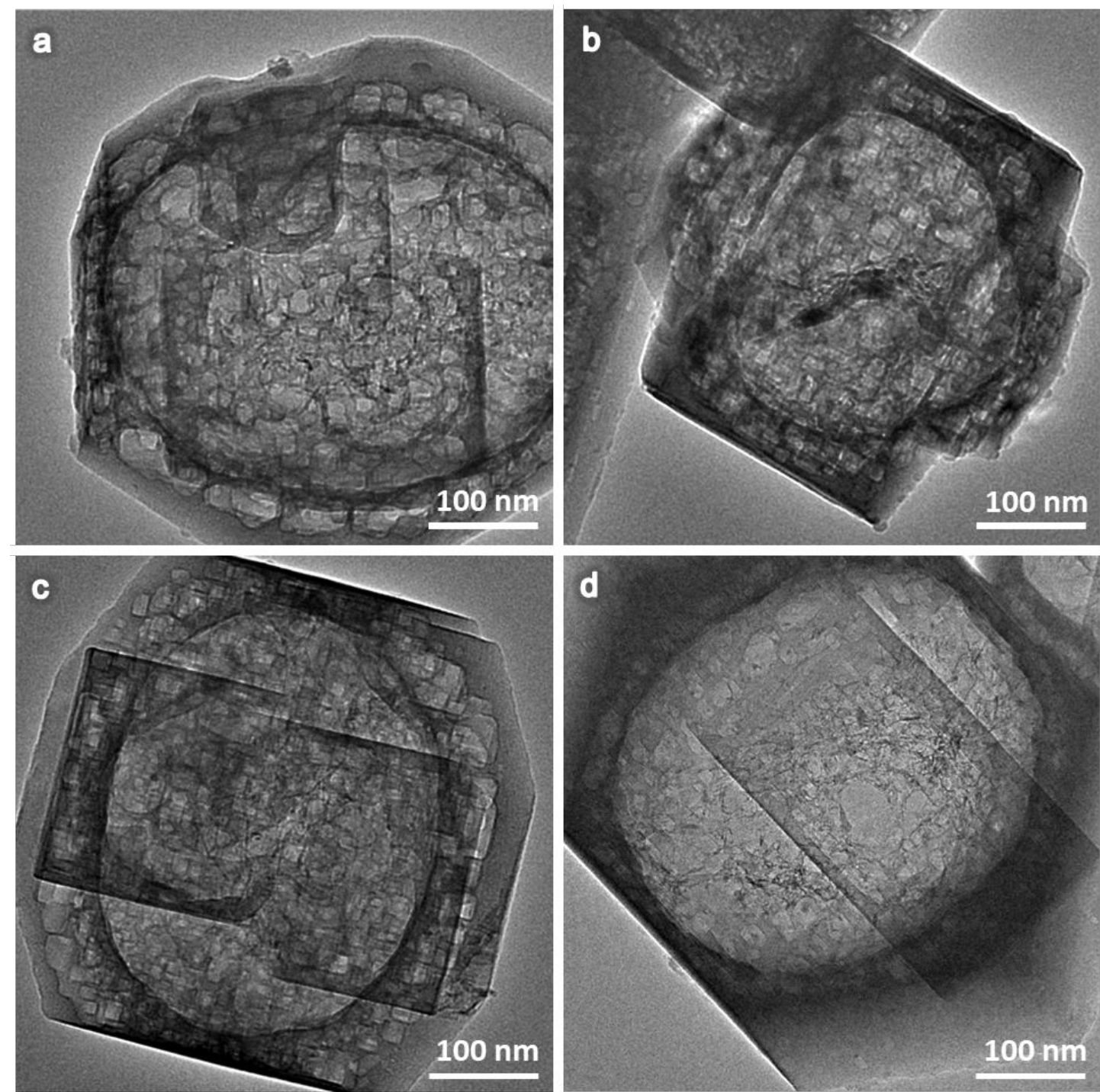

Figure S12. Representative TEM images ((a) to (d)) of Pd deposition without $\mathrm{H}_{2}$ reduction process. In this case, the hZ5-Cu sample was directly mixed with $\mathrm{Pd}$ precursor without prior $\mathrm{H}_{2}$ reduction. As the imbedded $\mathrm{Cu}$ was at +2 oxidation state, spontaneous galvanic replacement reaction cannot occur and no $\mathrm{Pd}$ formation was observed. 

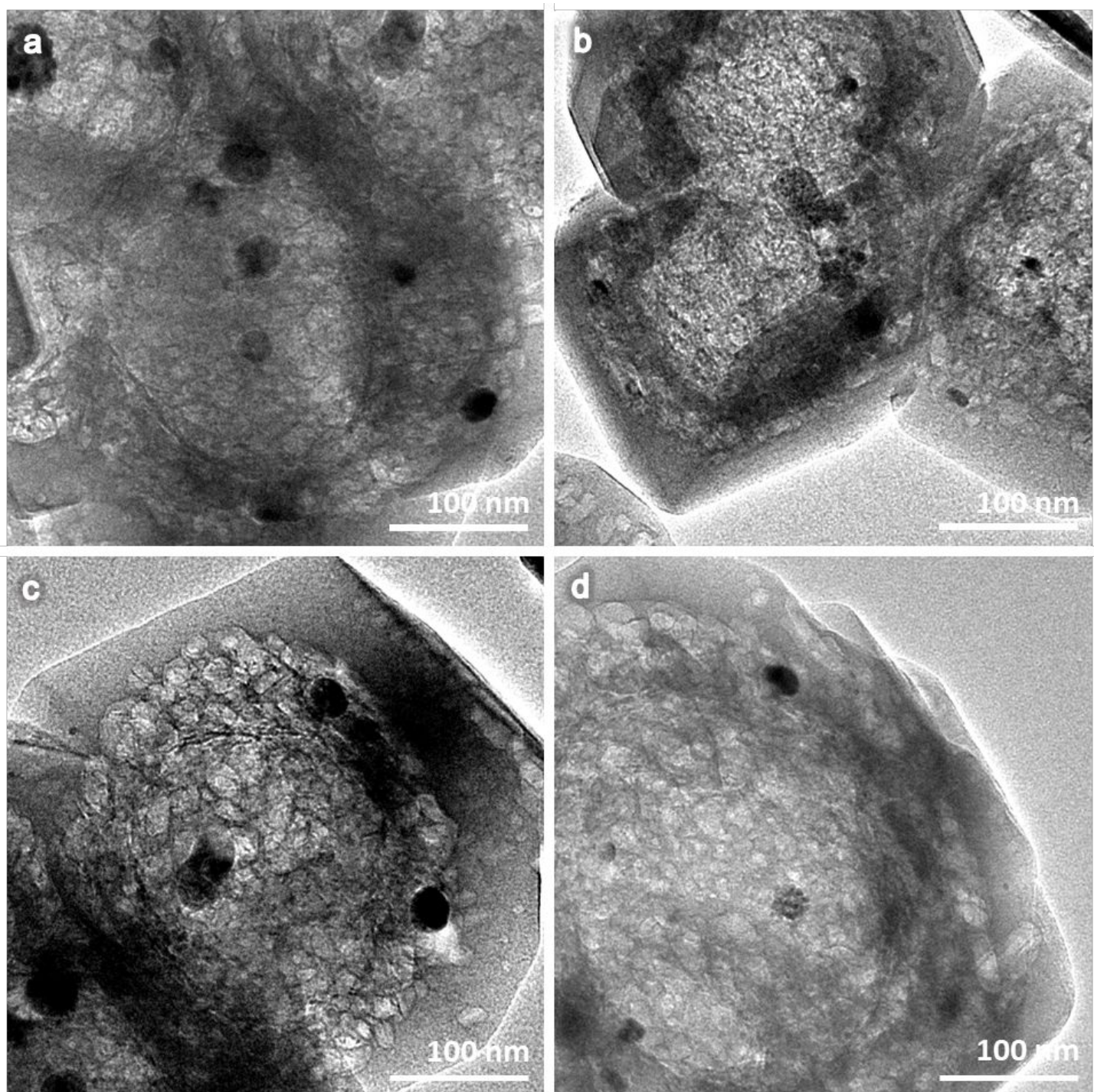

Figure S13. Representative TEM images ((a) to (d)) of hZ5-CuZn/Pd. This sample was synthesized using hydrogen-reduced $h Z 5-C u Z n$ instead of hydrogen-reduced $\mathrm{hZ5}-\mathrm{Cu}$. The introduction of metallic $\mathrm{Zn}$ has resulted in the formation of large $\mathrm{Pd}$ particles, because a greater difference of standard reduction potential between $\mathrm{Zn}$ and $\mathrm{Pd}$ leads to a faster $\mathrm{Pd}$ reduction rate. Hence, $\mathrm{Pd}$ was formed in a much larger particle size. 

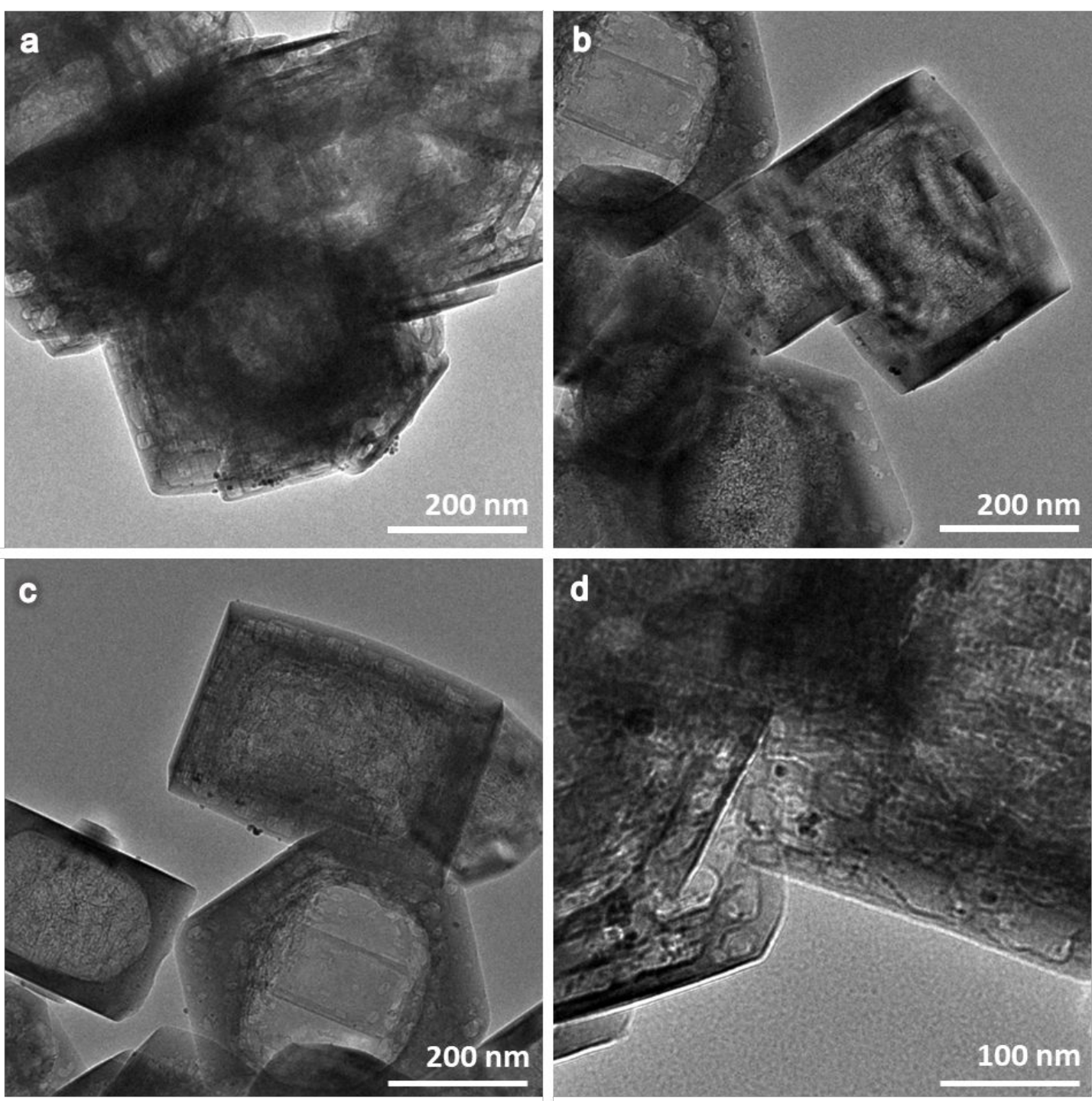

Figure S14. Representative TEM images ((a) to (d) at different magnifications) of hZ5-Cu/Pd sample prepared without the assistance of PVP. For this controlled experiment, hZ5-Cu before $\mathrm{H}_{2}$ reduction was mixed with $\mathrm{Pd}$ precursor, in the absence of PVP.

Note: This control experiment shows that $\mathrm{Pd}$ formation can also happen in solution without galvanic replacement reaction, leading to deposition of Pd NPs on the exterior of hollow ZSM-5. The particle formation of Pd can be inhibited by adding PVP in the solution, so that undesired $\mathrm{Pd}$ deposition can be avoided during the $\mathrm{Pd}$ encapsulation process.

Based on literature reports, it is known that ethanol could be used as an efficient reducing agent for synthesizing $\mathrm{Pd}$ nanoparticles under reflux condition while PVP could be used to control the particle size. ${ }^{1}$ As stated in literature, the increase of PVP/Pd ratio from 0.1 to 40 (molar ratio of PVP monomer to Pd) has led to a reduction in the obtained $\mathrm{Pd}$ particle size. Thus, $\mathrm{PVP}$ could successfully restricts the growth of Pd NPs.

In our experiment, it is believed the solvent ethanol could function as reducing agent 
even under room temperature, resulting in the formation of Pd NPs in a much slower rate. The PVP/Pd ratio is nearly 200 for our case and it is believed that formation of Pd NPs is practically negligible under such high PVP/Pd ratio.

The addition of PVP do not affect the galvanic replacement reaction and $\mathrm{Pd}$ formation within the hollow hZ5-Cu material. Upon dissolution in the reaction mixture, PVP was believed to exist as random coils with length longer than $1 \mathrm{~nm} .^{2}$ This dimension is greater than the channel dimension of ZSM- 5 shell, so there will be hardly any diffusion of PVP to the inside. As such, the galvanic replacement reaction and $\mathrm{Pd}$ deposition within the structure (between $\mathrm{Pd}$ ions and reduced $\mathrm{Cu}^{0}$ ) can be realized.

For illustration purpose, this sample was prepared with hZ5-Cu sample without $\mathrm{H}_{2}$ treatment. Only surface deposited Pd was present to avoid possible confusion.

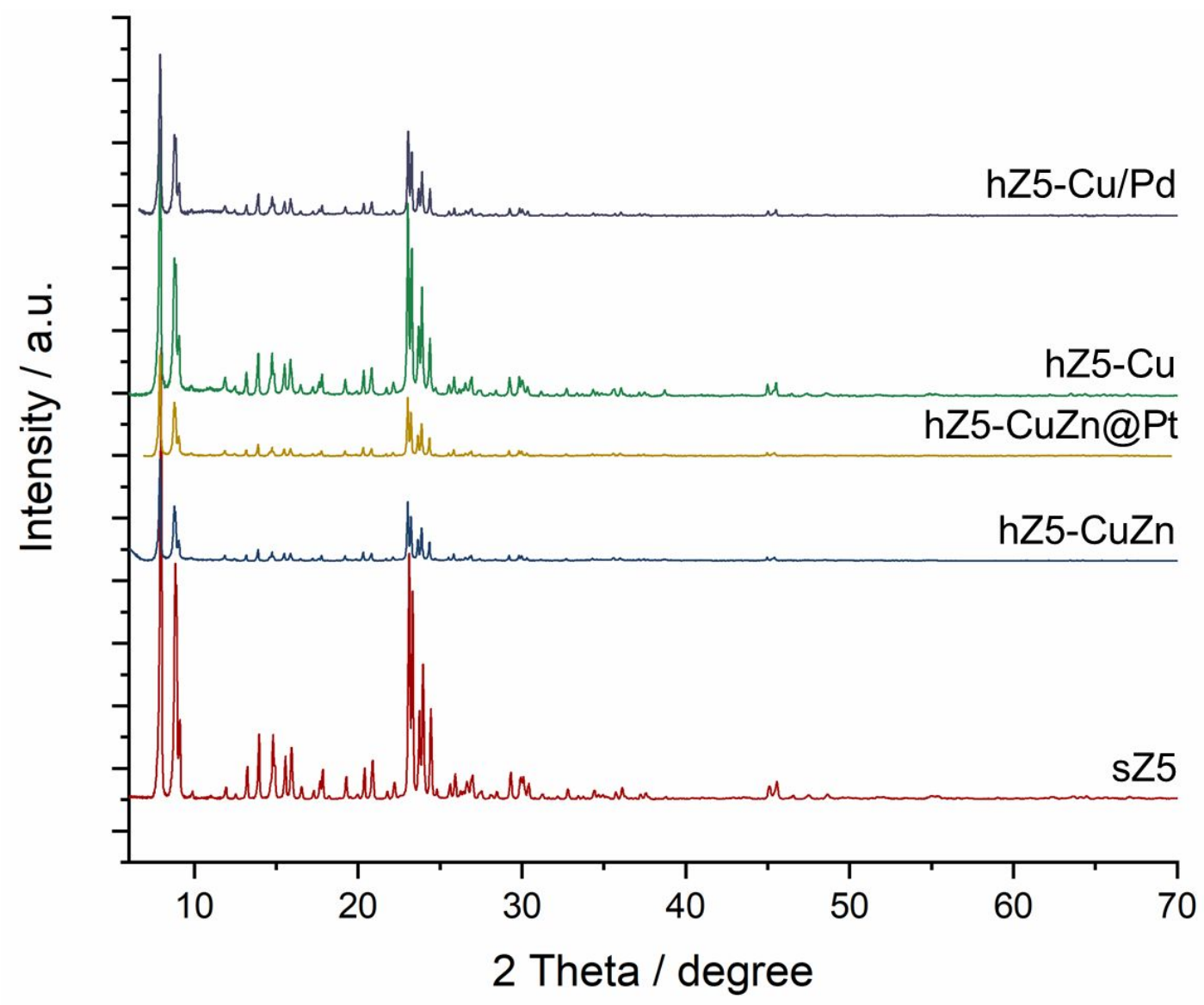

Figure S15. Powder XRD measurements of sZ5, hZ5-CuZn, hZ5-CuZn@Pt, hZ5-Cu and hZ5-Cu/Pd. The characteristic peaks of ZSM-5 phase were well preserved throughout all the synthetic steps. 

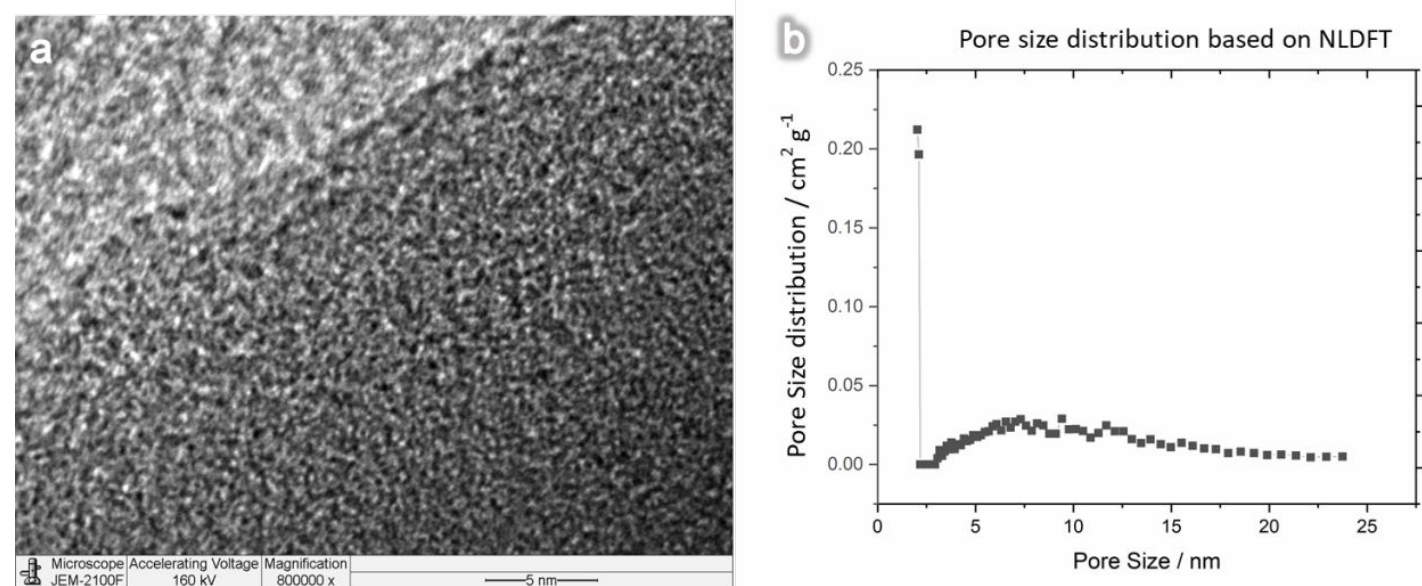

Figure S16. (a) High resolution TEM image taken at edge of a hollow ZSM- 5 crystal. The white color seen across the hollow shell indicates presence mesopores responsible for the $2 \mathrm{~nm}$ peak on pore size distribution plot; and (b) pore size distribution plot based on NLDFT method.

In the manuscript, the pore size distribution was calculated using BJH method and the $y$-axis indicates the incremental surface area. Based on that plot, hollow ZSM-5 sample only has a peak around $2 \mathrm{~nm}$. Based on the formation mechanism of selective dissolution, such mesopores were believed to be the result of local Aldeficient sites across the structure. A TEM image with high resolution has revealed the presence of such mesopores (Figure S12a, reflected as white colour in TEM image).

Apart from micropores originated from the ZSM-5 structure itself, the presence of mesopores with $2 \mathrm{~nm}$ diameter contributes to the most significant surface area change for the hollow ZSM-5 sample. The surface area increase from mesopores with larger diameter was insignificant when compared to the $2 \mathrm{~nm}$ one. Thus, these larger pores are not reflected in the pore size distribution plot. Pore size distribution with similar peak position has also been reported in other hollow ZSM-5 structure prepared with selective dissolution method. ${ }^{3}$

When the $\mathrm{N}_{2}$-sorption data was analysed with NLDFT method for pore size distribution (Figure S12b), the presence of micropores (first point in the plot indicates the presence of pores smaller than $2 \mathrm{~nm}$ which was assumed to be the micropores) and $2 \mathrm{~nm}$ mesopores (second point in the plot indicates the presence of mesopores with diameter near $2 \mathrm{~nm}$ ) were still major contributors to the surface area. In this NLDFT plot, presence of larger pores was reflected while noting that they are still less significant in the overall contribution. 

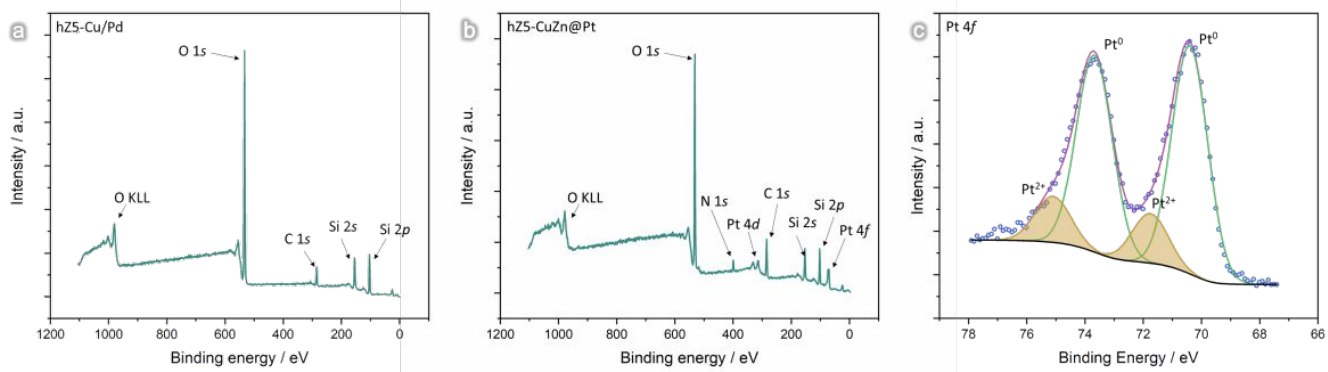

Figure S17. XPS full spectrum of (a) hZ5-Cu/Pd and (b) hZ5-CuZn@Pt samples, and (c) Pt 4f XPS spectrum of hZ5-CuZn@Pt sample.

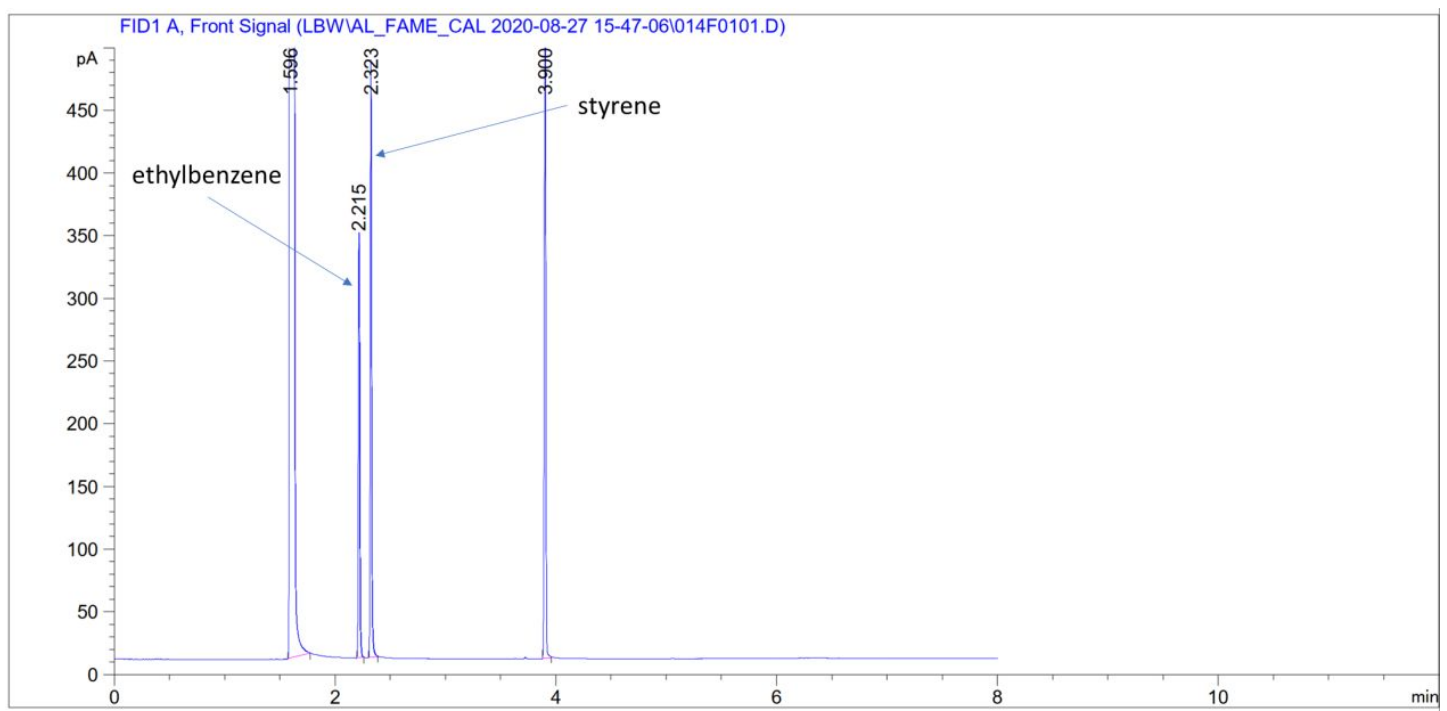

Figure S18. Gas chromatography of styrene hydrogenation after $5 \mathrm{~min}$ using $\mathrm{Pd} / \mathrm{C}$ as a catalyst. The peaks with the retention times at 1.59 and $3.90 \mathrm{~min}$ were solvent ethanol and internal standard dodecane, respectively.

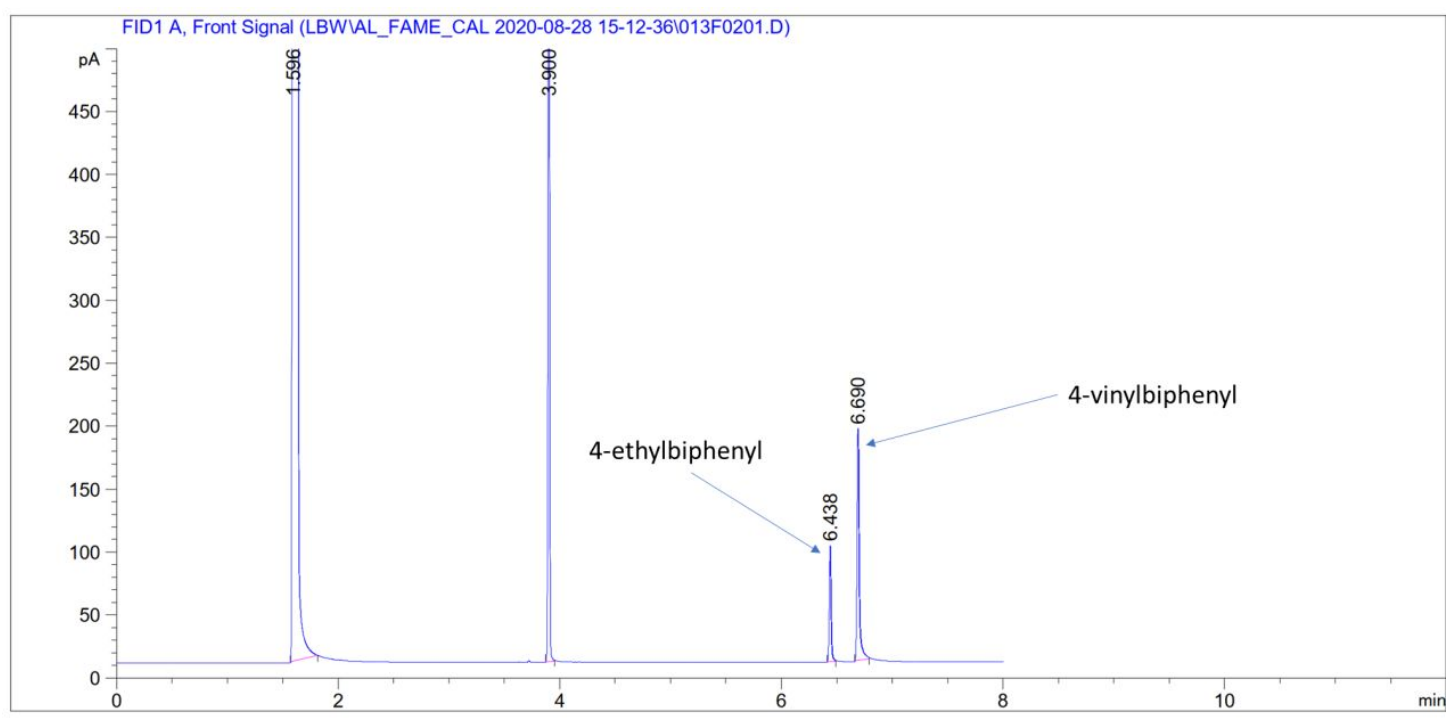

Figure S19. Gas chromatography of 4-vinylbiphenyl hydrogenation after 1 min using $\mathrm{Pd} / \mathrm{C}$ as a catalyst. The peaks with the retention times at 1.59 and 3.90 min were solvent ethanol and internal standard dodecane, respectively. 

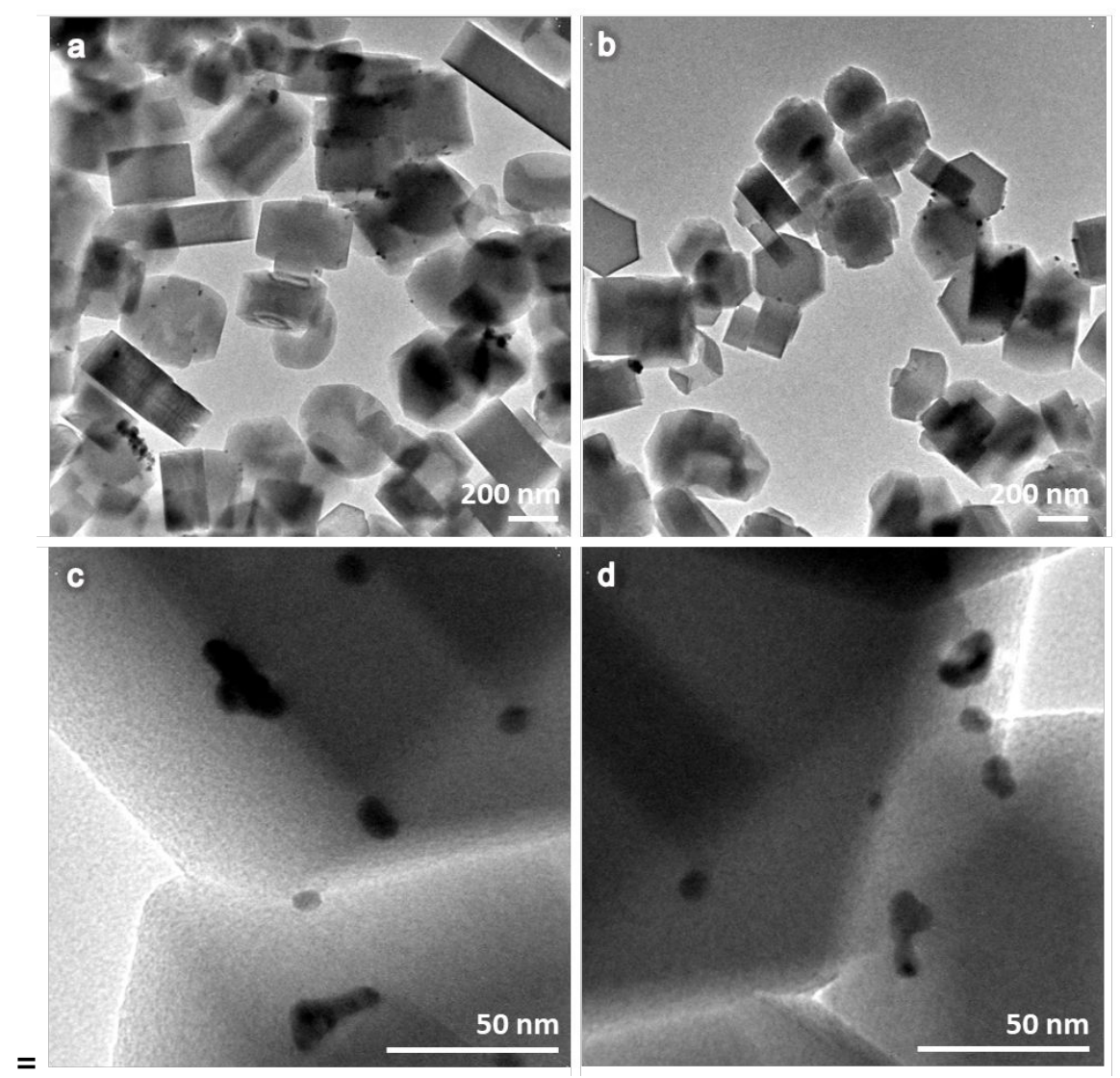

Figure S20. (a-d) Representative TEM images of sZ5@Pd sample at different magnifications.

The synthesis of this sZ5@Pd sample was carried out with an in-situ reduction method. Solid ZSM-5 sample prepared from Experiment section 2.3 was used as the support. Typically, $200 \mathrm{mg}$ of sZ5 sample was dispersed in $40 \mathrm{~mL}$ of methanol and sonicated for $10 \mathrm{~min} .8 \mathrm{~mL}$ of $\mathrm{PdCl}_{2}$ aqueous solution with $12 \mathrm{mM}$ concentration was then added to the suspension and stirred for $1 \mathrm{~h}$ at room temperature. Subsequently, $20 \mathrm{~mL}$ of $0.25 \mathrm{M}$ tetrabutylammonium borohydride in methanol solution was added to the mixture dropwisely. The resulting mixture was further stirred for $1 \mathrm{~h}$ at room temperature before centrifugation. The collected sample after centrifugation was washed twice with ethanol and dried in vacuum oven for later use.

TEM images of sZ5@Pd sample have been given below. The formation of Pd nanoparticles is clearly seen on the surface of sZ5 sample. All the as-formed Pd NPs were deposited on the exterior surface of the sZ5 support. On the basis of ICP-OES analysis, the Pd loading of this sZ5@Pd sample was 1.29 wt \%. 


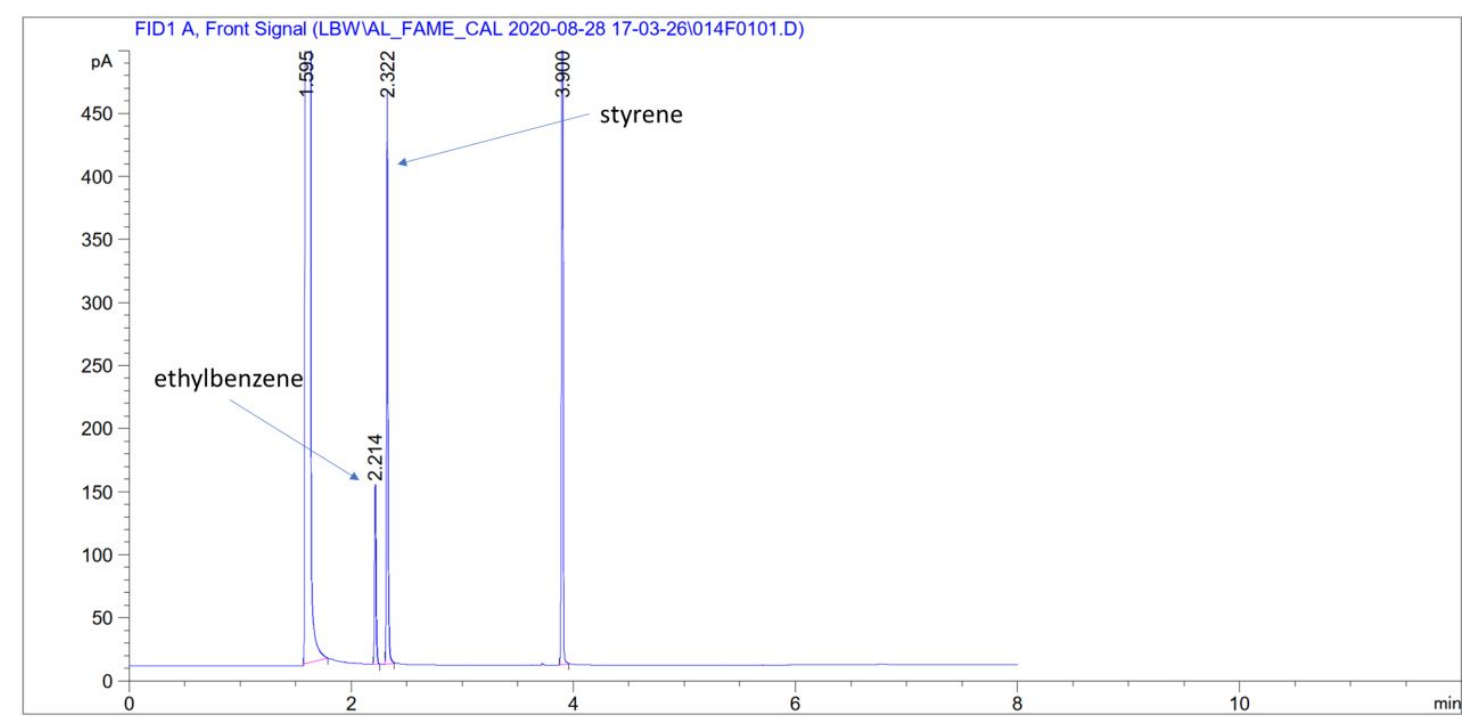

Figure S21. Gas chromatography of styrene hydrogenation after 5 min using hZ5$\mathrm{Cu} / \mathrm{Pd}$ as a catalyst. The peaks with the retention times at 1.59 and 3.90 min were solvent ethanol and internal standard dodecane, respectively.

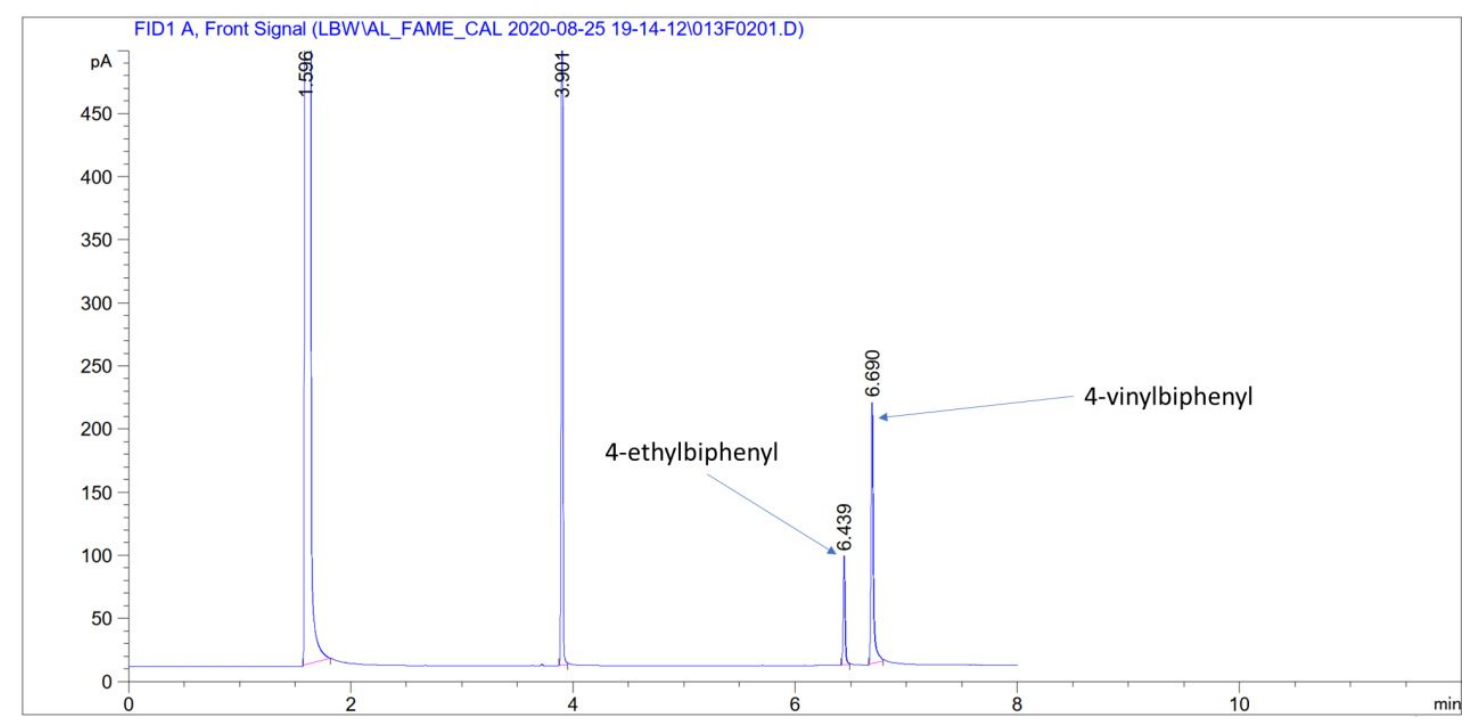

Figure S22. Gas chromatography of 4-vinylbiphenyl hydrogenation after $15 \mathrm{~min}$ using $\mathrm{hZ5}-\mathrm{Cu} / \mathrm{Pd}$ as a catalyst. The peaks with the retention times at 1.59 and 3.90 min were solvent ethanol and internal standard dodecane, respectively. 

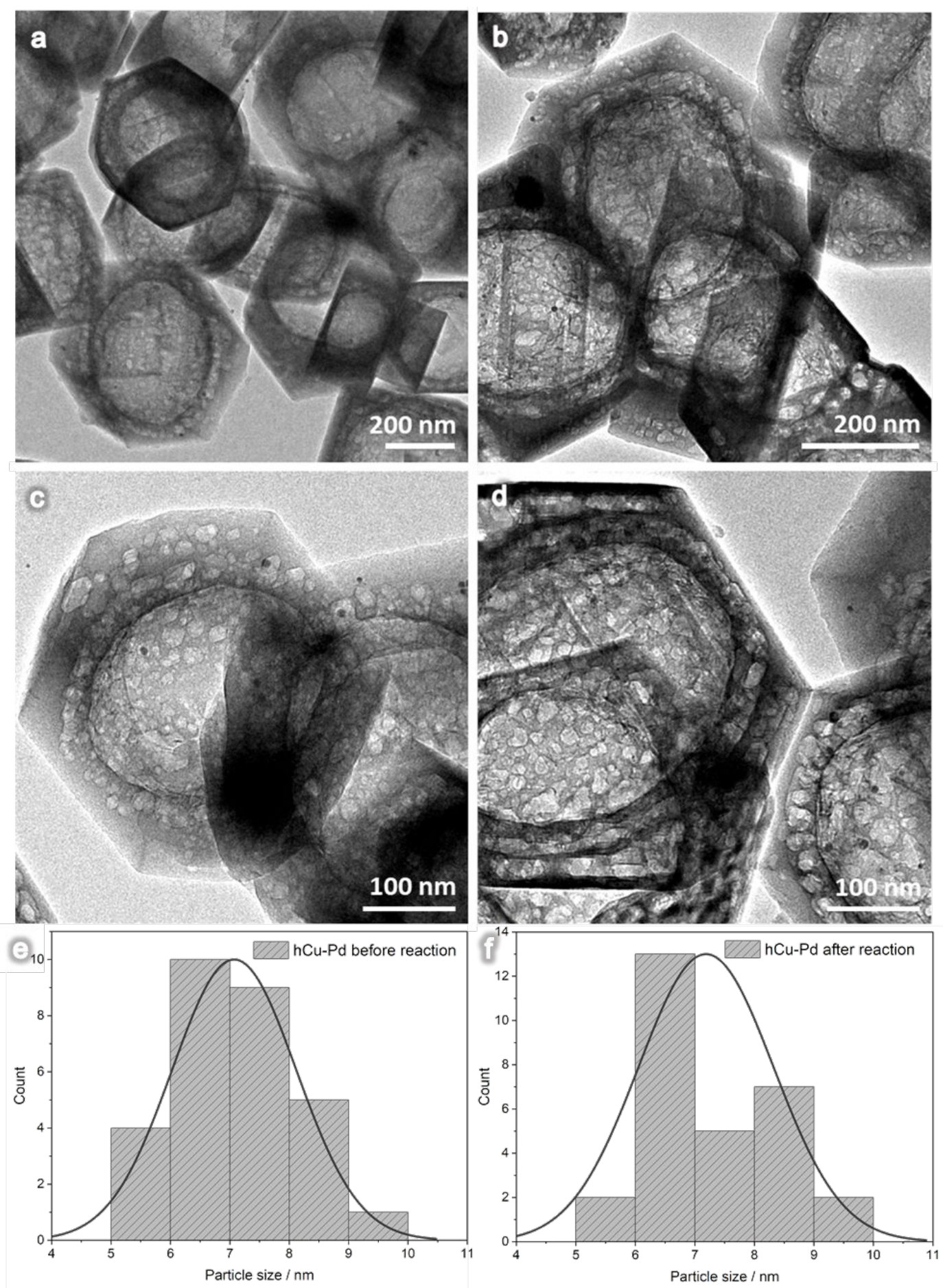

Figure S23. Representative TEM images ((a) to (d) at different magnifications) of $\mathrm{hZ5}-\mathrm{Cu} / \mathrm{Pd}$ spent catalyst after the hydrogenation reaction of styrene, and $\mathrm{Pd}$ particle size distribution of hCu-Pd catalyst before (e) and after (f) the hydrogenation reaction. The encapsulated Pd NPs were still confined within the hollow structure without observable aggregation, indicating the good structural stability of this catalyst.

Pd particle size was measured to be $7.0 \pm 0.9 \mathrm{~nm}$ before reaction and $7.3 \pm 1.1 \mathrm{~nm}$ after reaction, indicating no significant particle aggregation during reaction. 

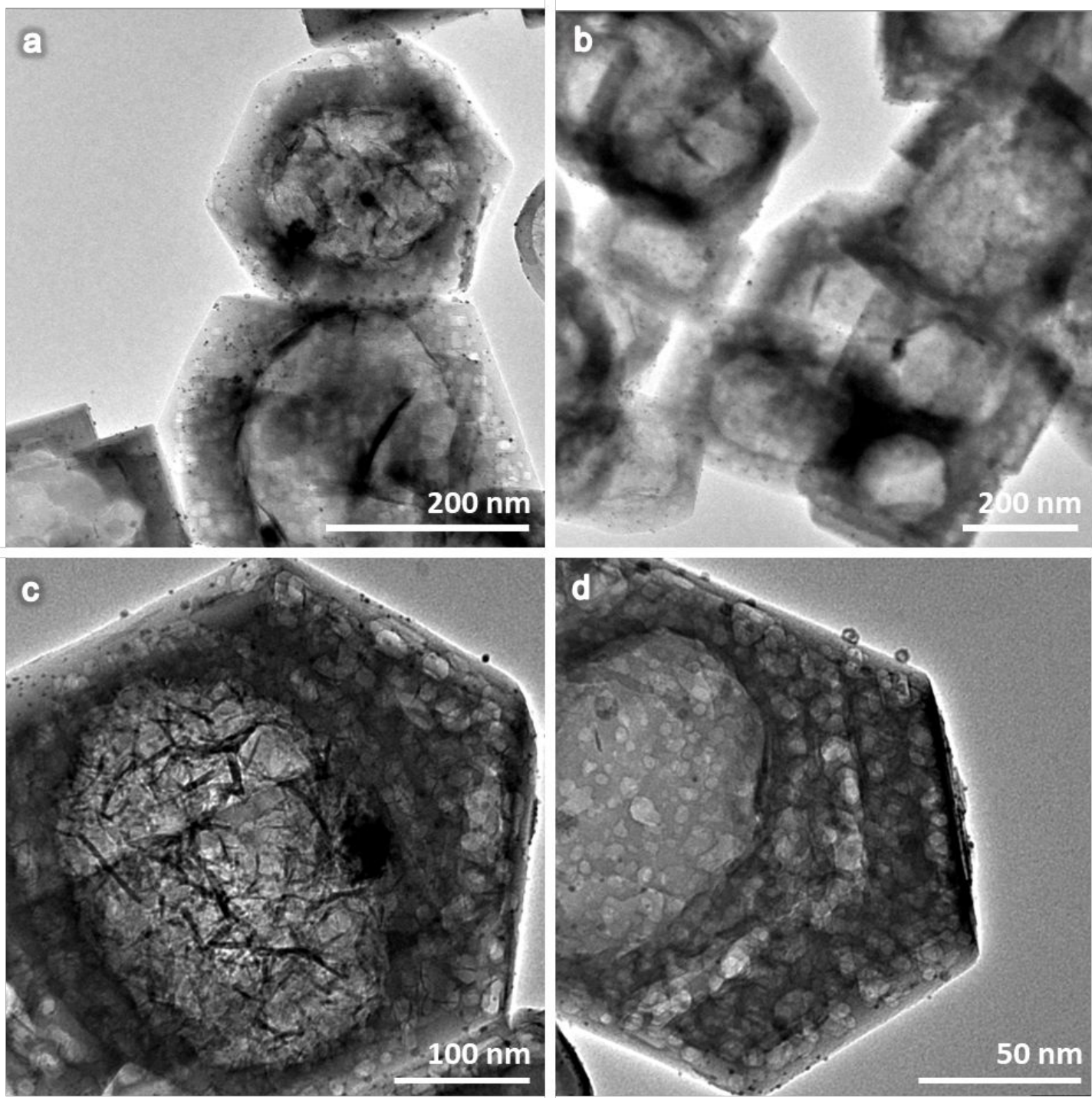

Figure S24. Representative TEM images ((a) to (d) at different magnifications) of hZ5-CuZn@Pt spent catalyst after the $\mathrm{CO}_{2}$ hydrogenation reaction. No significant structural deterioration was observed, showing that the catalyst is quite stable under the given reaction conditions. 

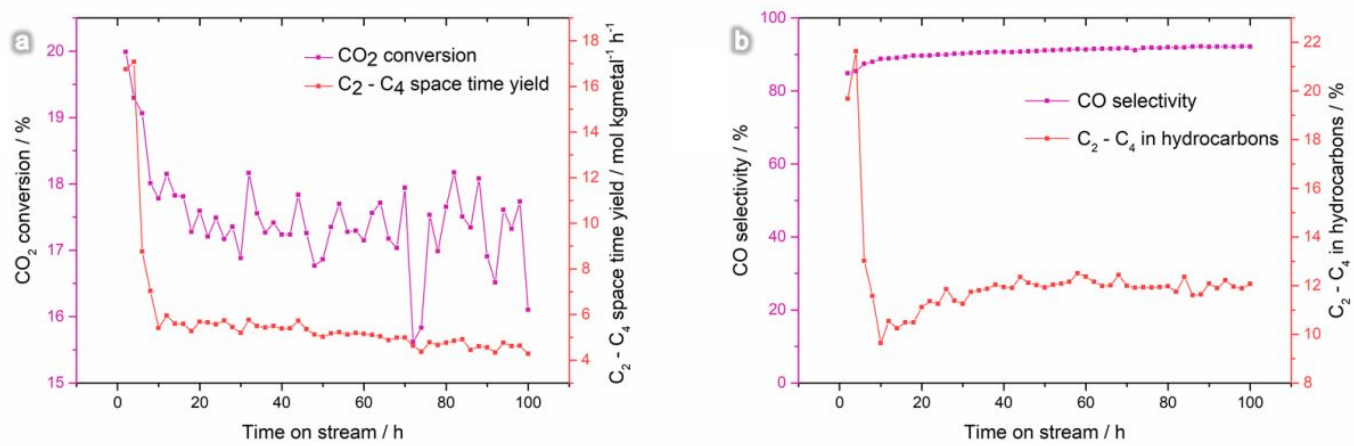

Figure S25. (a) $\mathrm{CO}_{2}$ conversion and $\mathrm{C}_{2}-\mathrm{C}_{4}$ space time yield and (b) CO selectivity and $\mathrm{C}_{2}-\mathrm{C}_{4}$ in hydrocarbons for stability test of hZ5-CuZn@Pt with $100 \mathrm{~h}$ on stream at $360{ }^{\circ} \mathrm{C}$.

To understand the stability of our catalyst, we have evaluated the hZ5-CuZn@Pt sample at $360{ }^{\circ} \mathrm{C}$ for $100 \mathrm{~h}$ with conversion data taken every $2 \mathrm{~h}$. The temperature was chosen as it gives the highest $\mathrm{C}_{2}-\mathrm{C}_{4}$ yield based on earlier experiments at different temperatures.

As seen from the figure, there is a significant decrease in catalyst performance for the initial $10 \mathrm{~h}$ on stream while the performance for subsequent $90 \mathrm{~h}$ on stream was rather stable. For the first $10 \mathrm{~h}$, the conversion of $\mathrm{CO}_{2}$ dropped slightly while the product selectivity of $\mathrm{CO}$ and $\mathrm{CH}_{4}$ increases. All these contributes to a reduction in the specific yield for $\mathrm{C}_{2}-\mathrm{C}_{4}$ products. For the next $90 \mathrm{~h}$ on stream, all these values fluctuate within a much narrower regime and the catalyst activity and selectivity were well preserved. 
Table S1. Detailed styrene and 4-vinylbiphenyl reaction data used for calculating TOFs.

\begin{tabular}{|c|c|c|c|c|c|}
\hline Entry & Catalyst & Reactant & $\begin{array}{l}\text { Time / } \\
\text { min }\end{array}$ & $\begin{array}{l}\text { Conversion } \\
/ \%\end{array}$ & $\begin{array}{l}\text { TOF } \\
/ \mathrm{min}^{-1}\end{array}$ \\
\hline 1 & $\mathrm{Pd} / \mathrm{C}$ & Styrene & 5 & 40.0 & 42.5 \\
\hline 2 & $\mathrm{Pd} / \mathrm{C}$ & 4-vinylbiphenyl & 1 & 29.7 & 39.5 \\
\hline 3 & sZ5@Pd & Styrene & 1 & 19.7 & 40.7 \\
\hline 4 & sZ5@Pd & 4-vinylbiphenyl & 0.5 & 47.6 & 49.1 \\
\hline 3 & hZ5-Cu/Pd & Styrene & 5 & 22.8 & 33.3 \\
\hline 4 & hZ5-Cu/Pd & 4-vinylbiphenyl & 15 & 25.5 & 3.1 \\
\hline
\end{tabular}

\section{Reaction conditions:}

Reactant solution: $1 \mathrm{mg}$ of $\mathrm{Pd} / \mathrm{C}(0.1 \mathrm{mg}$ of $\mathrm{Pd})$ or $20 \mathrm{mg}$ of $\mathrm{hZ}-\mathrm{Cu} / \mathrm{Pd}(0.072 \mathrm{mg}$ of $\mathrm{Pd})$ was used as catalyst $15 \mathrm{~mL}$ of ethanol as solvent and $0.1 \mathrm{~mL}$ of dodecane as internal standard, 0.5 mmol of styrene or $0.125 \mathrm{mmol}$ of 4-vinylbiphenyl as reactant. Reaction setting: $80^{\circ} \mathrm{C}$ with constant $\mathrm{H}_{2}$ bubbling at $20 \mathrm{~mL} / \mathrm{min}$.

TOFs in the above table were calculated according to moles of reactant converted and moles of Pd present in the catalyst.

Sample calculation of TOF (Entry 1):

Moles of styrene converted $=$ moles of styrene at start of reaction $\times$ styrene conversion $=0.5 \mathrm{mmol} \times 40 \%=0.2 \mathrm{mmol}$

Moles of Pd in catalyst $=\frac{\text { mass of Pd in catalyst }}{\text { molecular weight of Pd }}=\frac{0.1 \mathrm{mg}}{106.42 \mathrm{mg} / \mathrm{mmol}}=9.40$ $\times 10^{-4} \mathrm{mmol}$

TOF

$$
=\frac{\text { Moles of styrene converted }}{\text { moles of Pd in catalyst } \times \text { reaction time }}=\frac{0.2 \mathrm{mmol}}{9.40 \times 10^{-4} \mathrm{mmol} \times 5 \mathrm{~min}}=42.5
$$


Table S2. Detailed gas phase $\mathrm{CO}_{2}$ hydrogenation reaction data.

\begin{tabular}{|c|c|c|c|c|c|c|c|c|}
\hline Entry ${ }^{a}$ & Catalyst & $\begin{array}{c}\text { Temper } \\
\text { ature } \\
/^{\circ} \mathrm{C}\end{array}$ & $\begin{array}{c}\mathrm{CO}_{2} \\
\text { Conver } \\
\text { sion } / \%\end{array}$ & $\begin{array}{c}\text { methanol } \\
\text { selectivity } \\
\text { in } \\
\text { hydrocarbo } \\
\text { ns }^{b} / \%\end{array}$ & $\begin{array}{c}\mathrm{C}_{2}-\mathrm{C}_{4} \\
\text { selectivi } \\
\text { ty in } \\
\text { hydroca } \\
\text { rbons }^{\mathrm{b}} \\
/ \%\end{array}$ & $\begin{array}{c}\mathrm{C}_{5+} \\
\text { selectivity } \\
\text { in } \\
\text { hydrocarbo } \\
\text { ns }^{\mathrm{b}} / \%\end{array}$ & $\begin{array}{c}\mathrm{C}_{2}-\mathrm{C}_{4} \\
\text { selectivity } \\
\text { in all } \\
\text { products }^{\mathrm{c}} \\
/ \%\end{array}$ & $\begin{array}{c}\mathrm{C}_{2}-\mathrm{C}_{4} \\
\text { yield }^{\mathrm{d}} \\
\text { / mol } \\
\text { kgmetal } \\
{ }^{-1} \mathbf{h}^{-1}\end{array}$ \\
\hline 1 & $\begin{array}{l}\text { hZ5- } \\
\text { CuZn }\end{array}$ & 240 & N.A. & N.A. & N.A. & 0 & N.A. & N.A. \\
\hline 2 & $\begin{array}{l}\text { hZ5- } \\
\text { CuZn }\end{array}$ & 280 & 1.77 & 9.21 & 6.4 & 0 & 1.54 & 0.838 \\
\hline 3 & $\begin{array}{l}\text { hZ5- } \\
\text { CuZn }\end{array}$ & 320 & 5.55 & 2.56 & 9.66 & 0 & 2.75 & 4.77 \\
\hline 4 & $\begin{array}{l}\text { hZ5- } \\
\text { CuZn }\end{array}$ & 360 & 11.1 & 1.02 & 10.3 & 0 & 2.47 & 8.86 \\
\hline 5 & $\begin{array}{l}\text { hZ5- } \\
\text { CuZn }\end{array}$ & 400 & 19.3 & 0.44 & 9.34 & 0 & 2.33 & 13.5 \\
\hline 6 & $\begin{array}{c}\text { hZ5- } \\
\text { CuZn@ } \\
\text { Pt }\end{array}$ & 240 & 2.12 & 0 & 29.3 & 0 & 4.37 & 2.92 \\
\hline 7 & $\begin{array}{c}\text { hZ5- } \\
\text { CuZn@ } \\
\text { Pt }\end{array}$ & 280 & 4.67 & 0 & 17.0 & 0 & 3.06 & 4.00 \\
\hline 8 & $\begin{array}{c}\text { hZ5- } \\
\text { CuZn@ } \\
\text { Pt }\end{array}$ & 320 & 9.59 & 0 & 17.9 & 1.06 & 3.93 & 10.6 \\
\hline 9 & $\begin{array}{c}\text { hZ5- } \\
\text { CuZn@ } \\
\text { Pt }\end{array}$ & 360 & 16.9 & 0 & 16.6 & 0.81 & 3.05 & 14.9 \\
\hline 10 & $\begin{array}{c}\text { hZ5- } \\
\text { CuZn@ } \\
\text { Pt }\end{array}$ & 400 & 23.0 & 0 & 14.2 & 0 & 2.20 & 14.3 \\
\hline
\end{tabular}

${ }^{\text {a }}$ Reaction conditions: The reaction was carried out in a packed bed flow reactor with a 0.5 inch stainless steel tube reactor (interior diameter, $0.3125 \mathrm{inch}$ ) in a hot box at a temperature of $180{ }^{\circ} \mathrm{C}$. Catalysts (i.e., hZ5-CuZn or hZ5-CuZn@Pt; $200 \mathrm{mg}$ ) was loaded and reduced in a 
stream of $\mathrm{H}_{2}(50 \mathrm{~mL} / \mathrm{min})$ at $400{ }^{\circ} \mathrm{C}\left(3{ }^{\circ} \mathrm{C} / \mathrm{min}\right.$ ramp rate $)$ for $3 \mathrm{~h}$. Then, a mixed reaction gas $\left(\mathrm{N}_{2}: \mathrm{CO}_{2}: \mathrm{H}_{2}=15: 85: 255\right)$ was fed to the reactor at a flowrate of $50 \mathrm{~mL} / \mathrm{min}$ and the catalyst was evaluated at 30 bar from $240-400{ }^{\circ} \mathrm{C}$ in $40{ }^{\circ} \mathrm{C}$ steps. For each temperature, four GC readings were taken with $2 \mathrm{~h}$ time interval with the first reading taken $2 \mathrm{~h}$ after reaching setpoint temperature and the average of these four readings were presented in this table.

${ }^{\mathrm{b}}$ Product selectivity in hydrocarbons was calculated using the following formula:

$$
\begin{aligned}
& \text { Product selectivity } \\
& = \\
& \text { amount of } \mathrm{CH}_{4}+\text { amount of } \mathrm{MeOH}+\text { amount of } \mathrm{C}_{2}-\mathrm{C}_{4}+\text { amount of } \mathrm{C}_{5}+
\end{aligned}
$$

${ }^{\mathrm{c}} \mathrm{C}_{2}-\mathrm{C}_{4}$ selectivity in all products was calculated using the following formula:

$$
\begin{aligned}
& C_{2}-C_{4} \text { selectivity } \\
& \qquad=\frac{\text { amount of } C_{2}-C_{4}}{\text { amount of } \mathrm{CO}+\text { amount of } \mathrm{CH}_{4}+\text { amount of } \mathrm{MeOH}+\text { amount of } C_{2}-C_{4}}
\end{aligned}
$$

${ }^{\mathrm{d}} \mathrm{C}_{2}-\mathrm{C}_{4}$ yield was calculated using $\mathrm{C}_{2}-\mathrm{C}_{4}$ production rate and amount of metals in the catalyst.

For hZ5-CuZn sample, $\quad C_{2}-C_{4}$ yield $=\frac{\mathrm{CO}_{2} \text { conversion rate } \times C_{2}-C_{4} \text { selectivity in all products }}{\text { amount of } \mathrm{Cu}+\text { amount of } \mathrm{Zn}}$

ForhZ5-CuZn@Pt sample,

$$
C_{2}-C_{4} \text { yield }=\frac{\mathrm{CO}_{2} \text { conversion rate } \times C_{2}-C_{4} \text { selectivity in all products }}{\text { amount of } \mathrm{Cu}+\text { amount of } \mathrm{Zn}+\text { amount of } \mathrm{Pt}}
$$




\section{References}

1. Teranishi, T.; Miyake, M., Size Control of Palladium Nanoparticles and Their Crystal

Structures. Chemistry of Materials 1998, 10 (2), 594-600.

2. Haaf, F.; Sanner, A.; Straub, F., Polymers of N-Vinylpyrrolidone: Synthesis,

Characterization and Uses. Polymer Journal 1985, $17(1), 143-152$.

3. Dai, C.; Zhang, A.; Liu, M.; Guo, X.; Song, C., Hollow ZSM-5 with Silicon-Rich Surface,

Double Shells, and Functionalized Interior with Metallic Nanoparticles and Carbon Nanotubes.

Advanced Functional Materials 2015, 25 (48), 7479-7487. 